\title{
Variability and Predictors of Mothers and Fathers' Socialization Behaviors and Bidirectional Links with Their Preschoolers Socio-Emotional Competences
}

\author{
Stéphanie Mazzone, Nathalie Nader-Grosbois \\ Psychological Sciences Research Institute, Chair Baron Frère in Specialized Education, Université Catholique de Louvain, \\ Louvain-la-Neuve, Belgium \\ Email:nathalie.nader@uclouvain.be
}

How to cite this paper: Mazzone, S. and Nader-Grosbois, N. (2017) Variability and Predictors of Mothers and Fathers' Socialization Behaviors and Bidirectional Links with Their Preschoolers Socio-Emotional Competences. Journal of Behavioral and Brain Science, 7, 621-653.

https://doi.org/10.4236/jbbs.2017.712043

Received: October 17, 2017

Accepted: November 27, 2017

Published: November 30, 2017

Copyright $\odot 2017$ by authors and Scientific Research Publishing Inc. This work is licensed under the Creative Commons Attribution International License (CC BY 4.0).

http://creativecommons.org/licenses/by/4.0/

\begin{abstract}
In their Parental Socialization of Emotions model, Eisenberg, Cumberland and Spinrad (1998) differentiated parents' Emotion-Related Socialization Behaviours (ERSBs) that support their child's socio-emotional development: their reactions to their child's emotions, their discussions about emotions with the child and the expressions of their own emotions in the family. The crosssectional study focused on the variability of parents' ERSBs according to children's and parents' characteristics (Study 1) and included 167 mothers and 152 fathers of preschoolers. The short-term longitudinal study examined the interaction between parents' ERSBs and children's socio-emotional abilities (Theory of Mind, emotional regulation and social adjustment) (Study 2) in 53 two-parent families and their children, with a 6 months interval. In Study 1, parents' ERSBs, their emotional competences and children's personality were assessed by means of questionnaires. In Study 2, we combined direct and indirect measures to assess children's socio-emotional competences. Results of Study 1 indicated that parental ERSBs were mainly predicted by children's personality, such as emotional stability and parents' emotional competences, such as communication about their own emotions. Moreover, we observed a differential sensitivity between mothers and fathers toward children's personality. Results of Study 2 revealed that both mothers and fathers socialized their children's socio-emotional competences, particularly by the way of emotion-related conversations with their children. Mothers' emotion-related conversations predicted children's Theory of mind abilities and social adjustment, while fathers' emotion-related conversations predicted children's emotional regulation. In addition, fathers' reactions to their child-
\end{abstract}


ren's emotions were predicted by children's socio-emotional competences. These studies highlighted bidirectional effects between parents' behaviours and children's development. They emphasized also the importance to better identify predictors of parents' ERSBs in order to know on which target the professionals should intervene.

\section{Keywords}

Parental Emotion-Related Socialization Behaviours, Preschool Period, Socio-Emotional Competences

\section{Introduction}

In order to deepen knowledge about how preschoolers develop their emotional competences and social adjustment, searchers study the role of family environment, including parents' practices, and how preschoolers influence their parents' socialization behaviours. These studies could give guidelines to prevent emotional and behavioural disorders in young children, taking into account the bidirectional links between both parents' practices and children socio-emotional abilities. More specifically, the recent literature emphasized the importance to examine how mothers and fathers help their child to regulate and understand emotions or mental states in social situations that could sustain their social adjustment [1] [2] [3].

In their heuristic model of Parental Emotion-Related Socialization Behaviours (ERSBs), Eisenberg, Cumberland and Spinrad [4] explained how parents learn to develop their children socio-emotional development, by their reactions to the child's emotions, their emotion-related conversations with the child and their emotional expression in the family. About parents' supportive reactions, they may help the child to solve the socio-emotional problem, or encourage the child to express emotions. During conversations on emotions, parents may explain and ask questions about emotions felt by the child, or another person, or a character in a story. About non-supportive parents' reactions, they may deny the seriousness of the child's emotions or feel embarrassed by their child's emotional expression. These authors consider parents and children's individual variables that could make vary this socialization process. These present studies focused specifically on parents' reactions to their child's emotions and parents' emotion-related conversations, in examining the variability depending on children's and parents' variables and predictors of these ERSBs.

\subsection{ERSBs and Individuals' Characteristics}

The process model of the determinants of parenting developed by Belsky ([5] p. 84) have yet highlighted that parents' and children's characteristics as significant determinants of parenting, including notably dispositional traits or personality [6]. Despite the increasing number of studies in this field, much less is known about individual's characteristics as predictors of parent's ERSBs. In order to 
improve family intervention in favour of socio-emotional development, it is essential to identify the predictors of each parent's ERSBs that could be protective or risk factors.

Concerning children's characteristics, the majority of studies explored children's gender and age, as determinants of parent's reactions to their children's emotions (e.g., [1] [2] [3] [7]) and parent's emotion-related conversations (e.g., [8] [9] [10]). Only some studies explored the variability of parental ERSBs according to the child's temperament, in particular the emotionality. Jones, Eisenberg, Fabes and MacKinnon [11] reported the interaction between the child's negative emotional intensity and maternal reactions to the child's negative emotions. The level of emotional intensity in children and maternal emotion-focused responses interact to predict children's social competences. Children were highest in social competences when their level of negative emotional intensity was low and when mothers displayed a high level of emotion-focused responses. Nevertheless, children's temperament may directly predict parents' ERSBs. Indeed, temperamental dimensions, such as negative emotionality (tendency to feel negative emotions) and effortful control (consisting of inhibitory control, attentional focusing, low intensity pleasure and perceptual sensitivity), were significantly linked with the quality of mothers' emotion-related conversations about a past event, with their children. Mothers provided more details about the event and asked more questions when they perceived their child as having a high level of negative emotionality and/or effortful control [12].

Concerning parents' characteristics, numerous studies revealed that parents' reactions to their child's emotions (e.g., [1] [13] [14]) and parents' emotionrelated conversations (e.g., [10] [15] [16]) vary depending on the parent's gender. Except the parent's gender, researchers have largely overlooked other parents' characteristics as potential predictors of their ERSBs. Recently, Manczak et al. [17] explored how mother's and father's personality predict emotion-related conversations with their children. Results indicated that mother's personality, in particular social closeness (the extent to which she desires and values relationship with others), predict greater expertise in emotion-related conversations about positive and negative events. No significant association was obtained about father's personality and these conversations. Even if the intervention must consider the parents' gender and personality as antecedent factors, it's important to target also parents' predictors that could be used as a lever to guide their ERSBs. Therefore, we need studies that should explore other parents' characteristics or competences. For example, Meyer, Raikes, Virmani, Waters and Thompson [18] showed that mothers' own beliefs and knowledge about emotions, including the ability of regulate their own emotions, predict their reactions to child's emotions. When mothers felt able to regulate their own negative moods and maintain positive emotions, they displayed more supportive reactions (such as problem-focused responses and encouragement) and less nonsupportive reactions (such as distress) to child's negative emotions. These results are in accordance with previous studies suggesting that parents' cognitions of 
their own affects and emotional wellbeing are core characteristics to be available and responsive to their child's emotions [19] [20] [21].

Before implementing a parental program and intervene on ERSBs, it seems to be crucial to know antecedents' factors in children and in parents. On the one hand, this can contribute to raise mothers and fathers' awareness that their own characteristics and those of their child could influence their behaviours, and not necessarily in the same way for mothers and fathers. On the other hand, this would help to identify those on which it is possible to intervene or not.

\subsection{ERSBs and Socio-Emotional Development}

Many studies revealed that supportive parental reactions to child's emotions are related to better child's abilities in Theory of Mind (ToM) (e.g., [1] [2]), or in emotional regulation (ER) (e.g., [3] [18] [22]) and in social adjustment (e.g., [7] [11]). While parental non-supportive reactions may impede the child's socio-emotional development. Several researchers highlighted also the importance of conversations about emotions in the family to support children's ToM (e.g., [8] [16] [23]), ER development (e.g., [24]) and social adjustment (e.g., [25] [26]). Although these studies provide an overview on the socialization process, they use a one-time cross-sectional design, which makes it difficult to disentangle directions of effects. Therefore, longitudinal studies are required in view to identify the predictive links between parents' ERSBs and children's socio-emotional competences. Some longitudinal studies focused on only one parents' ERSBs, reactions or emotion-related conversations, and some other combined these two types of ERSBs. Perry, Calkins, Nelson, Leerkes and Marcovitch [27] identified a predictive link between maternal supportive reactions to preschoolers' negative emotions and emotional regulation 1 year later. About emotion-related conversations, LaBounty et al. [16] showed that when mothers talked about emotions with their 3,5 year-old children, by asking questions around a picture book depicted emotion-eliciting situations, these children had better emotional understanding at age 5,5. While paternal emotion-related conversations predict children's understanding of beliefs and false-beliefs, two years later. In using a composite score of maternal supportive ERSBs (supportive reactions to children's negative emotions, emotion talk and maternal positive expressiveness), results revealed that mothers' supportive ERSBs predict children's self-awareness of happiness and sadness, 1 year later. On the contrary, maternal non-supportive ERSBs seems to have a detrimental effect on children's self-awareness of sadness [28]. To test predictive and bidirectional links or effects between these parents' ERSBs and preschoolers' socio-emotional abilities, longitudinal studies should be led. To our knowledge, no longitudinal study focused on preschool period to examine this potential effect of children's socio-emotional competences on parents' ERSBs. At the school period, a study reported that children's emotional competences also affect parents' ERSBs: specifically, the children's emotional regulation abilities at age 6 - 8 predict parents' punitive reactions to their child- 
ren's negative emotions at age 8 - 10 [29].

All of these studies have improved our understanding of the role of parental ERSBs in children's socio-emotional development, but there is still some gap in the literature. Firstly, there is a discrepancy between studies including only mothers and those including both parents. While, it is important to include fathers in parenting studies because family should be conceptualized as a system of interdependent relationship [30]. Moreover, previous studies (e.g., [1] [16] [17]) revealed results and effects that differed between mothers and fathers. Therefore, it is important to study maternal and paternal models independently in view to emphasized potential gender differences and accordingly adapt parental programs. Secondly, many studies focused on one type of parents' ERSBs and/or on one children's socio-emotional domain. They offer only a very partial knowledge about this socialization process. It is necessary to lead studies integrating distinct socio-emotional abilities in children, and different ERSBs in mothers and in fathers, in order to have a nuanced and overall overview of the socialization process. Finally, as the majority of studies in the field used a one-time crosssectional design, making hard the results interpretation about mutual effects of these children's competences and parents' ERSBs, we need longitudinal studies to investigate interaction between parents' ERSBs and children's socio-emotional competences to prevent possible difficulties in preschool period. This is congruent with the approach of bidirectionality developed in developmental and clinical psychology, emphasizing the mutual influence in parent-child relationshipfrom parent to child and from child to parent-that it is essential to consider in family therapy [31] [32] [33].

\subsection{The Current Studies}

Two studies focused on mothers and fathers' reactions and conversations on emotions and preschoolers' abilities in ToM, ER and social adjustment. Study 1 used a one-time cross-sectional design and Study 2 implemented a short-term longitudinal design with two waves of collect data.

The objective of Study 1 is to explore the variability of maternal and paternal ERSBs (reactions and conversations) according to parents' and children's characteristics (see Figure 1). Among children's characteristics, we take into account their age and personality, as predictors of mothers' and fathers' ERSBs, independently. Indeed, each parent could be differentially sensitive to some children's characteristics. We expected that each parent's reactions to their child's emotions and emotion-related conversations vary according to the five factors of personality, in particular emotional stability and extraversion in their child. Among parent's characteristics, we consider each parent's age, level of education and emotional competences, including representations about emotions, communication of emotions and emotional regulation. We postulated that each parent's ERSBs could vary according to her or his own emotional representation, communication or regulation. For example, parents who well regulated 


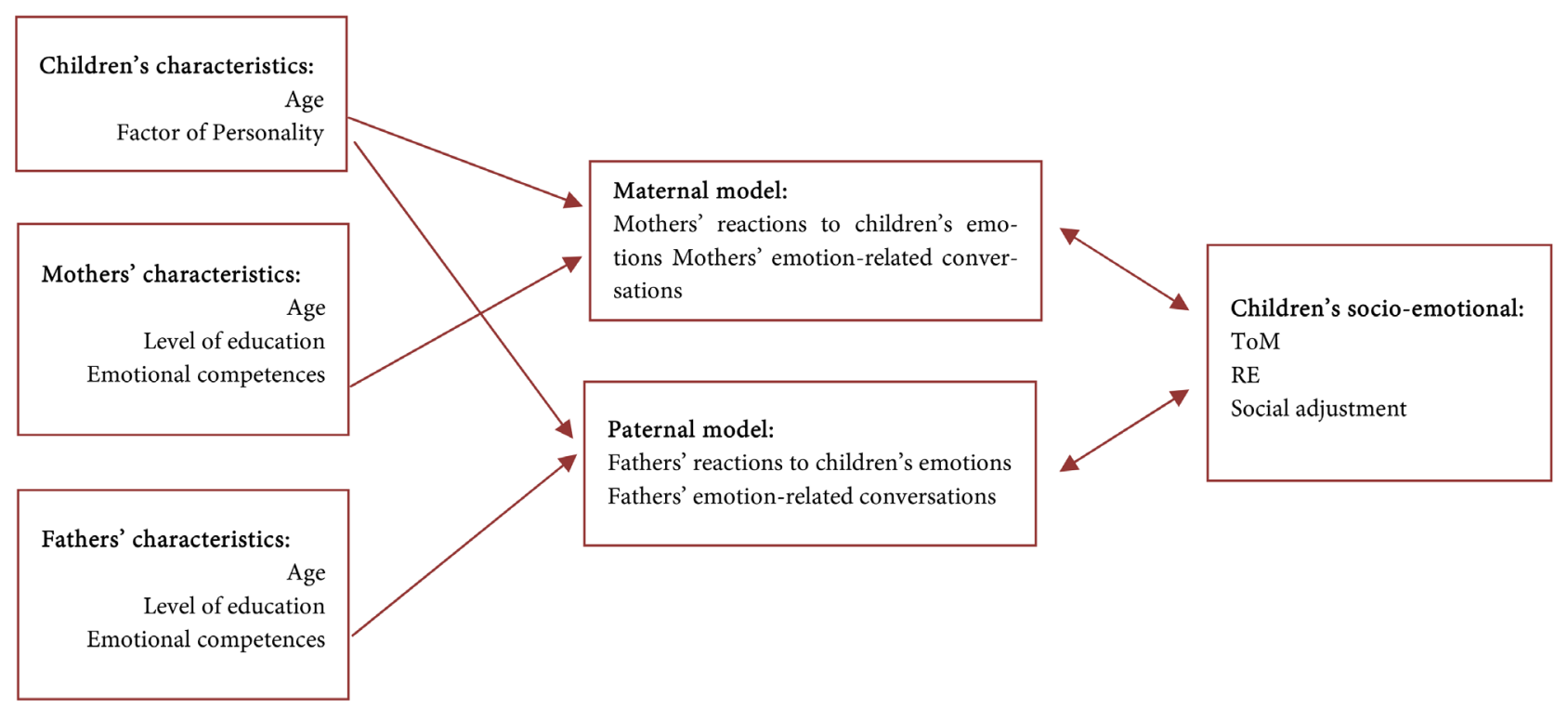

Figure 1. Model of Parental Socialization of Emotions and their links with preschoolers' socio-emotional competences.

their emotions or who are comfortable to communicate about emotions would be more likely to display more supportive reactions and to converse about emotions with their child.

The goal of Study 2 is to investigate the interaction between parents' ERSBs, both reactions and conversations, and children's socio-emotional competences, including ToM, ER and social adjustment (see Figure 1). Firstly, we examine how parents' ERSBs display at the first Wave (W1) predict children's socio-emotional competences at the second Wave (W2) 6 months later, by taking into account the children's competences at W1. Secondly, we examine how children's socio-emotional competences at W1 predict parents' ERSBs display at W2, by taking into account parents' ERSBs display at W1. As in previous studies in the field, we expected that each parents' ERSBs predict children's socio-emotional competences 6 months later, in particular supportive behaviours. Moreover, as parenting literature support that parent-child effects are bidirectional, we hypothesize that children's socio-emotional competences predict parents' ERSBs 6 months later.

\section{Study 1: Variability of Maternal and Paternal ERSBs According to Parents' and Children's Characteristics}

\subsection{Method}

\subsubsection{Participants and Procedure}

Participants were 167 mothers and 152 fathers of preschoolers ( 84 boys and 83 girls) aged between 2 years and 11 months and 6 years and 1 month $(M=4.71$; $\mathrm{SD}=0.74)$. The recruitment has been done in French-speaking Belgian schools between November 2013 and December 2015. The average age of mothers and fathers were 35.33 years $(S D=4.59)$ and 38.10 years $(S D=5.18)$ respectively. Both mothers and fathers had a high level of education: in most cases either 
graduate school ( $42.4 \%$ of mothers, $36.2 \%$ of fathers), or university ( $47.7 \%$ of mothers, $44.9 \%$ of fathers). Families were predominantly Caucasian and the majority of children lived with both their biological parents (96.2\%).

Parents were informed about the research project by their children's school. When they had signed the consent form for their participation, teachers and parents received their respective questionnaires. All participants were informed that they could withdraw from the research at any time and that data would be treated anonymously and used only for the study.

\subsubsection{Measures}

\section{1) Questionnaires completed by parents about themselves}

Parental Reactions toward Positive and Negative Emotions ([34] combined version of CCNES, [35] and QRPEPE, [36]). This questionnaire assesses how parents react to their children's negative and positive emotions by the use of hypothetical scenarios in which a child experiences a negative or positive emotion. This version contained six hypothetical scenarios illustrating fear, sadness and anger and two scenarios illustrating happiness. For the negative scenarios, the six alternative parents' reactions are comforting responses, encouragement of expression of emotion, problem-focused responses, distress, minimizing responses and punitive responses. For scenarios involving joy, the four types of parents' reactions are socialization, encouragement, reprimand and discomfort. The parent is asked to rate the probability of responding to the script in each of possible strategies when he/she experiences this situation with his/her child, using a 7-point scale ranging from 1 ("very unlikely") to 7 ("very likely").

This measure was validated on 328 parents. The factor analysis revealed two subscales (supportive reactions and non-supportive reactions) for negative and positive emotions. For the negative scenarios, Cronbach's alpha was 0.78 and 0.81 , while for the joy scenarios, it was 0.77 and 0.62 .

Questionnaire of Parent-Child Conversations about Emotions (QPCCE, [37]). This questionnaire assesses how parents converse about the four basic emotions with their child. It includes 24 items illustrating emotion-related conversations between parents and their child that are supportive (e.g. When my child came home angry after being out (at school, with friends or family, etc.), we talked together about his/her feelings) or non-supportive (e.g. When I talked to my child about negative feelings (sadness, fear, anger) and we disagreed, I argued in order to bring him/ her round to my viewpoint). Using a 4-point scale ranging from " 0 time" to " 5 times and more", the parent indicates the number of times he/she has experienced the situation with their child during the last two weeks. It also provided a "not appropriate" response option, which could be used if the situation had not arisen during the last two weeks. The second part of the questionnaire presents a checklist of emotional terms for the four basic emotions (joy, sadness, anger and fear). Parents were asked to mark all terms that they usually use with their children.

This measure was validated on 300 parents. The factor analysis revealed a sin- 
gle factor with reversed items for the non-supportive strategies. Cronbach's alpha for the total score was 0.91 .

Dimensions of Openness to Emotions (DOE, [38]). This 36-items questionnaire assesses parents' openness to emotional processes according to their subjective representations. Based on the multidimensional model of affect processing, this measure involve six subscales: The Cognitive-Conceptual Representation of Emotions (REPCOG), the Communication of Emotion (COMEMO), The Perception of Internal and External Bodily Indicators of Emotions (PERINT and PEREXT), The Regulation of Emotion (REGEMO) and The Normative Restrictions of Affectivity (RESNOR). In this study, only three subscales corresponding to parents' emotional competences were used. The REPCOG subscale assesses individual knowledge of emotions and in particular the ability to differentiate affects such as emotions, moods or emotional episodes (e.g. I can accurately name every emotion or mood that I am feeling). The Communication of Emotion (COMEMO) subscale evaluates individuals' ability to express (by facial expression, voice, gestures, etc.) their emotions or to intentionally verbalized the affective state they are experiencing in order to share and communicate with others (e.g. For me, it is important to communicate to others how I am feeling). The Regulation of Emotion (REGEMO) subscale assesses individual's emotional regulation competences (e.g. I manage to calm my feelings even in difficult situations). The parent was asked to indicate on a 5-point scale ranging to 0 ("not at all") to 4 ("completely") to what extent each item corresponded to him.

The factor analysis revealed the 6 factors corresponding to respective theoretical dimensions, with Cronbach's alpha values of 0.83 for the REPCOG subscale, of 0.81 for the COMEMO subscale and of 0.75 for the REGEMO subscale.

2) Questionnaires completed by teachers about the children

Bipolar Rating Scales based on the Five-Factor Model (EBMCF, [39]). Based on the Five-Factor Model, this questionnaire assesses adults' perception of children's personality. It contains 25 pairs of adjectives, five for each factor in the model (extraversion, agreeableness, conscientiousness, emotional stability and openness), one of which constitutes the positive pole and the other the negative pole (e.g., untidy-meticulous). The "extraversion" factor corresponds to children who seek contact with others as being full of energy and often experiencing positive emotions. The "agreeableness" factor describes children who are inclined to be empathic and cooperative due to their optimistic view of human nature. The "emotional stability" factor characterises children who are stable, calm and less emotionally reactive. The "conscientiousness" factor corresponds to children who are meticulous, careful and organized. The "openness" factor describes children who are imaginative, curious and creative. The teachers were asked to indicate on a 9-point scale to what extent each characteristic correspond to the child.

The validation was conducted with 321 children. The factor analysis revealed the 5 expected factors, for which Cronbach's alpha was between 0.70 and 0.93 . 


\subsection{Results}

\subsubsection{Data Analysis}

First, descriptive statistics analyses (means and standard deviation) and inter-correlations, using Pearson correlation analysis, were performed. Moreover, to explore the percentage of variance of parents' ERSBs explained by both parents' and children's characteristics, linear regression analyses by the stepwise method were applied. As in previous studies (e.g., [3] [26] [40]) having a moderate sample size, the use of multiple linear regression was evaluated as a good method in light of the objectives of the Study 1.

\subsubsection{Preliminary Analyses}

Table 1 presents means and standard deviations for all measures and Table 2 presents inter-correlations between parental ERSBs, children's personality and parent's emotional competences. As indicated in Table 1, the level of children's emotional stability is significantly lower than the other four factors of personality. Compared with the average level of the sample, fathers' level of communication of emotions is lower. Moreover, compared with other kind of reactions, both mothers and fathers displayed less distress and punitive responses to their child's negative emotions and discomfort to their child's positive emotions.

\subsubsection{Variability of Parents' ERSBs According to Parents' and Children's Characteristics}

We present two separate models to analyze predictors of maternal and paternal ERSBs. For children's characteristics, we entered children's chronological age in step 1 and scores in the five factors of personality in step 2. Concerning parent's characteristics, we entered parent's age and level of education in step 3 and scores in emotional competences (representations of emotions, communication of emotion and regulation of emotion) were added in step 4. Items were evaluated for multicollinearity using the variance inflation index (VIF). For the two models (maternal and paternal), there are no multicollinearity between variables.

Table 3 presents the results of significant predictors of maternal reactions and conversations. Concerning children's characteristics as predictors of maternal reactions to their child's emotions, Model 2c, including children's chronological age and emotional stability explained $7 \%$ of the variance of maternal punitive responses to the child's negative emotions (-E). Secondly, about mothers' characteristics as predictors of maternal reactions, Model $1 \mathrm{~d}$ showed that mother's knowledge of emotions explained $6 \%$ of the variance of maternal discomfort to the child's positive emotions (+E). Finally, concerning the influence of both children's characteristics and mothers' characteristics on maternal reactions, Model 2a, including the child's extraversion and the mother's age explained $8 \%$ of the variance of maternal comforting to the child's $-\mathrm{E}$. The Model $2 \mathrm{~b}$ including mothers' ability to communicate their emotions and children's emotional stability explained $6 \%$ of the variance of maternal problem-focused responses to the child's -E. No significant result was obtained for maternal encouragement, 
Table 1. Means and standard deviations for all measures of Study 1.

\begin{tabular}{|c|c|c|c|}
\hline & & $M$ & SD \\
\hline \multicolumn{4}{|l|}{ Children's personality $(\operatorname{Max}=9)$} \\
\hline Extraversion & & 6.03 & 1.67 \\
\hline Agreeableness & & 6.88 & 1.37 \\
\hline Conscientiousness & & 6.37 & 1.51 \\
\hline Emotional stability & & 5.85 & 1.27 \\
\hline Openness & & 7.08 & 1.27 \\
\hline \multicolumn{4}{|l|}{ Mother's emotional competences $($ Max $=4)$} \\
\hline Representations of emotions & & 2.78 & 0.63 \\
\hline Communication of emotions & & 2.23 & 0.75 \\
\hline Regulation of emotions & & 2.12 & 0.71 \\
\hline \multicolumn{4}{|l|}{ Maternal ERSBS } \\
\hline \multicolumn{4}{|l|}{ Reactions to negative emotions $(\mathrm{Max}=7)$} \\
\hline & Comforting & 4.92 & 0.87 \\
\hline & Problem-focused & 5.66 & 0.84 \\
\hline & Encouragement of expression of emotion & 4.56 & 1.13 \\
\hline & Distress & 2.32 & 0.66 \\
\hline & Punitive & 2.03 & 0.74 \\
\hline & Minimizing responses & 3.67 & 1.10 \\
\hline \multicolumn{4}{|l|}{ Reactions to positive emotions ( $\mathrm{Max}=7$ ) } \\
\hline & Socialization & 5.53 & 1.32 \\
\hline & Encouragement & 4.60 & 1.28 \\
\hline & Reprimand & 3.96 & 1.35 \\
\hline & Discomfort & 2.40 & 1.37 \\
\hline Emotion-related conversations $(\mathrm{Max}=4)$ & & 2.59 & 0.41 \\
\hline Emotional terms & & 12.98 & 5.45 \\
\hline \multicolumn{4}{|l|}{ Father's emotional competences ( $\operatorname{Max}=4)$} \\
\hline Representations of emotions & & 2.66 & 0.64 \\
\hline Communication of emotions & & 1.88 & 0.71 \\
\hline Regulation of emotions & & 2.61 & 0.59 \\
\hline \multicolumn{4}{|l|}{ Paternal ERSBs } \\
\hline \multicolumn{4}{|l|}{ Reactions to negative emotions ( $\mathrm{Max}=7$ ) } \\
\hline & Comforting & 4.83 & 0.87 \\
\hline & Problem-focused & 5.30 & 0.88 \\
\hline & $\begin{array}{l}\text { Encouragement of } \\
\text { expression of emotion }\end{array}$ & 4.06 & 0.98 \\
\hline & Distress & 2.47 & 0.76 \\
\hline & Punitive & 2.40 & 0.78 \\
\hline & Minimizing responses & 4.30 & 0.97 \\
\hline \multicolumn{4}{|l|}{ Reactions to positive emotions ( $\mathrm{Max}=7$ ) } \\
\hline & Socialization & 5.58 & 1.19 \\
\hline & Encouragement & 4.47 & 1.27 \\
\hline & Reprimand & 4.13 & 1.43 \\
\hline & Discomfort & 2.28 & 1.16 \\
\hline Emotion-related conversations $(\mathrm{Max}=4)$ & & 2.36 & 0.39 \\
\hline Emotional terms & & 11.55 & 5.91 \\
\hline
\end{tabular}

Notes. $M=$ mean, $\mathrm{SD}=$ standard deviation, ERSBs = Emotion Related Socialization Behaviours. 
Table 2. Inter-correlations between mother and father's reactions and parents' and children's individual characteristics.

\begin{tabular}{|c|c|c|c|c|c|c|c|c|c|c|c|}
\hline & \multirow{2}{*}{$\begin{array}{c}\text { Children's } \\
\text { CA }\end{array}$} & \multicolumn{5}{|c|}{ Children's personality } & \multirow{2}{*}{$\begin{array}{l}\text { Parent's } \\
\text { age }\end{array}$} & \multirow{2}{*}{$\begin{array}{l}\text { Parent's } \\
\text { level of } \\
\text { education }\end{array}$} & \multicolumn{3}{|c|}{ Parent's emotional competences } \\
\hline & & $\mathrm{E}$ & $\mathrm{A}$ & $\mathrm{C}$ & ES & $\mathrm{O}$ & & & REPCOG & COMEMO & REGEMO \\
\hline \multicolumn{12}{|l|}{$\begin{array}{l}\text { Maternal ERSBS } \\
\text { Reactions to negative } \\
\text { emotions }\end{array}$} \\
\hline Comforting & -0.126 & $-0.158^{*}$ & -0.050 & -0.092 & 0.013 & -0.120 & $-0.236^{\star *}$ & $-0.186^{\star}$ & $0.156^{*}$ & 0.077 & -0.060 \\
\hline Problem-focused & 0.063 & -0.029 & -0.023 & -0.081 & 0.158 & -0.090 & 0.037 & 0.122 & 0.104 & $0.222^{* *}$ & 0.041 \\
\hline $\begin{array}{l}\text { Encouragement of } \\
\text { expression of emotion }\end{array}$ & 0.014 & -0.132 & -0.031 & -0.070 & -0.123 & -0.133 & 0.057 & -0.076 & 0.110 & $0.165^{*}$ & -0.002 \\
\hline Distress & $-0.171^{*}$ & -0.099 & -0.019 & -0.109 & 0.046 & -0.095 & $-0.188^{*}$ & 0.067 & -0.131 & -0.093 & -0.113 \\
\hline Punitive & -0.136 & 0.028 & -0.104 & -0.141 & $-0.163^{*}$ & -0.042 & -0.112 & .086 & -0.082 & 0.017 & 0.053 \\
\hline Minimizing responses & -0.088 & -0.057 & 0.105 & -0.138 & -0.001 & -0.063 & -0.151 & -0.111 & 0.051 & 0.112 & -0.040 \\
\hline \multicolumn{12}{|l|}{$\begin{array}{l}\text { Reactions to positive } \\
\text { emotions }\end{array}$} \\
\hline Socialization & 0.040 & -0.098 & 0.066 & 0.022 & $0.164^{*}$ & -0.004 & 0.031 & 0.099 & 0.010 & 0.069 & 0.031 \\
\hline Encouragement & $-0.217^{\star *}$ & -0.089 & -0.068 & -0.114 & -0.134 & -0.143 & -0.125 & -0.059 & 0.080 & -0.066 & 0.136 \\
\hline Reprimand & 0.045 & 0.040 & 0.064 & -0.155 & 0.052 & 0.049 & -0.011 & 0.065 & -0.075 & -0.029 & $-0.203^{\star *}$ \\
\hline Discomfort & -0.116 & -0.020 & -0.074 & -0.013 & 0.045 & 0.083 & 0.001 & 0.079 & $-0.214^{* *}$ & -0.059 & -0.102 \\
\hline $\begin{array}{l}\text { Emotion-related } \\
\text { conversations }\end{array}$ & 0.012 & -0.069 & -0.049 & -0.055 & 0.004 & -0.019 & -0.017 & 0.039 & 0.110 & 0.084 & -0.047 \\
\hline Emotional terms & 0.108 & .013 & -0.049 & 0.017 & -0.062 & 0.036 & 0.058 & 0.120 & 0.044 & -0.049 & 0.101 \\
\hline \multicolumn{12}{|l|}{$\begin{array}{l}\text { Paternal ERSBS } \\
\text { Reactions to negative } \\
\text { emotions }\end{array}$} \\
\hline Comforting & -0.039 & -0.015 & 0.041 & -0.035 & -0.082 & 0.005 & -0.096 & -0.046 & 0.042 & -0.079 & 0.054 \\
\hline Problem-focused & 0.018 & $-0.168^{*}$ & -0.012 & -0.075 & -0.013 & -0.129 & 0.074 & -0.029 & 0.133 & 0.118 & 0.021 \\
\hline $\begin{array}{l}\text { Encouragement of } \\
\text { expression of emotion }\end{array}$ & -0.064 & -0.095 & -0.101 & 0.029 & -0.001 & 0.012 & $0.209^{*}$ & -0.020 & 0.131 & $0.173^{\star}$ & 0.061 \\
\hline Distress & 0.112 & -0.004 & 0.040 & $-0.188^{\star}$ & -0.134 & -0.036 & $-0.270^{\star *}$ & -0.086 & 0.001 & 0.033 & -0.034 \\
\hline Punitive & -0.016 & 0.012 & -0.130 & $-0.298^{\star *}$ & -0.153 & -0.113 & -0.128 & -0.050 & -0.079 & 0.100 & -0.040 \\
\hline Minimizing responses & -0.090 & -0.065 & 0.130 & 0.014 & 0.073 & 0.022 & $-0.210^{*}$ & -0.133 & 0.018 & -0.091 & $0.186^{*}$ \\
\hline \multicolumn{12}{|l|}{$\begin{array}{l}\text { Reactions to positive } \\
\text { emotions }\end{array}$} \\
\hline Socialization & 0.019 & -0.046 & -0.092 & -0.010 & -0.002 & -0.069 & 0.017 & 0.062 & 0.105 & -0.035 & -0.003 \\
\hline Encouragement & -0.049 & -0.050 & 0.037 & -0.019 & -0.043 & 0.002 & -0.107 & 0.112 & 0.157 & 0.090 & 0.140 \\
\hline Reprimand & 0.975 & 0.144 & 0.029 & -0.107 & -0.145 & 0.065 & -0.119 & -0.107 & -0.036 & -0.054 & -0.065 \\
\hline Discomfort & 0.083 & 0.035 & -0.135 & -0.075 & $-0.170^{\star}$ & -0.071 & -0.038 & 0.022 & -0.075 & -0.127 & -0.139 \\
\hline $\begin{array}{l}\text { Emotion-related } \\
\text { conversations }\end{array}$ & 0.031 & 0.066 & 0.034 & 0.142 & -0.021 & 0.097 & 0.015 & -0.076 & $0.272^{\star *}$ & 0.077 & -0.034 \\
\hline Emotional terms & 0.053 & 0.111 & 0.130 & 0.150 & 0.019 & $0.201^{\star}$ & $0.198^{\star}$ & -0.062 & 0.123 & 0.112 & 0.030 \\
\hline
\end{tabular}

Notes. $\mathrm{CA}=$ chronological age, $\mathrm{E}=$ Extraversion, $\mathrm{A}=$ Agreeableness, $\mathrm{C}=$ Conscientiousness, $\mathrm{ES}=$ Emotional stability, $\mathrm{O}=$ Openness, REPCOG $=$ Cognitive-Conceptual Representation of Emotions, COMEMO = Communication of Emotion, REGEMO $=$ Regulation of Emotion, ERSBs $=$ Emotion Related Socialization Behaviours, ${ }^{*} p<0.05,{ }^{* *} p<0.01$.

distress and minimizing responses to the child's -E, for maternal socialization, encouragement and reprimand to the child's $+\mathrm{E}$. 
Table 3. Predictors of maternal ERSBs.

\begin{tabular}{|c|c|c|c|c|c|}
\hline \multirow[b]{2}{*}{ Predictors } & \multicolumn{5}{|c|}{ Comforting_-E } \\
\hline & $\mathrm{B}$ & $\mathrm{SE} / \mathrm{B}$ & $\beta$ & $R_{a d i j i}^{2}$ & $F$ \\
\hline Model 1a & & & & 0.02 & $40.337^{\star}$ \\
\hline Child's extraversion & -00.089 & 0.043 & $-0.176^{*}$ & & \\
\hline Model 2a & & & & 0.08 & $80.891^{\star *}$ \\
\hline Child's extraversion & -0.072 & 0.042 & $-0.143^{*}$ & & \\
\hline \multirow[t]{2}{*}{ Mother's age } & -0.049 & 0.016 & $-0.247^{\star \star}$ & & \\
\hline & \multicolumn{5}{|c|}{ Problem-focused_-E } \\
\hline Predictors & $\mathrm{B}$ & $\mathrm{SE} / \mathrm{B}$ & $\beta$ & $R_{a d j i j}^{2}$ & $F$ \\
\hline Model 1b & & & & 0.04 & $60.919^{*}$ \\
\hline Mother's communication of emotions & 0.262 & 0.100 & $0.220^{*}$ & & \\
\hline Model 2b & & & & 0.06 & $50.648^{* *}$ \\
\hline Mother's communication of emotions & 0.268 & 0.099 & $0.225^{\star *}$ & & \\
\hline \multirow[t]{2}{*}{ Child's emotional stability } & 0.114 & 0.055 & $0.055^{*}$ & & \\
\hline & \multicolumn{5}{|c|}{ Punitive_-E } \\
\hline Predictors & $\mathrm{B}$ & $\mathrm{SE} / \mathrm{B}$ & $\beta$ & $R_{a d j j}^{2}$ & $F$ \\
\hline Model 1c & & & & 0.04 & $60.202^{*}$ \\
\hline Child's age & -0.017 & 0.007 & $-0.209^{*}$ & & \\
\hline Model 2c & & & & 0.07 & $50.774^{* *}$ \\
\hline Child's age & -0.016 & 0.007 & $-0.192^{*}$ & & \\
\hline \multirow[t]{2}{*}{ Child's emotional stability } & -0.109 & 0.048 & $-0.188^{*}$ & & \\
\hline & \multicolumn{5}{|c|}{ Discomfort_+E } \\
\hline Predictors & $\mathrm{B}$ & $\mathrm{SE} / \mathrm{B}$ & $\beta$ & $R_{a d j i}^{2}$ & $F$ \\
\hline Model 1d & & & & 0.06 & $100.128^{* *}$ \\
\hline \multirow[t]{2}{*}{ Mother's representation of emotions } & -0.566 & 0.178 & $-0.263^{\star *}$ & & \\
\hline & \multicolumn{5}{|c|}{ Emotion-related conversation } \\
\hline Predictors & B & $\mathrm{SE} / \mathrm{B}$ & $\beta$ & $R_{a d j i j}^{2}$ & $F$ \\
\hline Model 1e & & & & 0.09 & $50.425^{\star *}$ \\
\hline Level of education & 0.105 & 0.036 & $0.327^{\star *}$ & & \\
\hline Mother's age & -0.026 & 0.010 & $-0.238^{*}$ & & \\
\hline Model 2e & & & & 0.14 & $50.807^{\star *}$ \\
\hline Level of education & 0.120 & 0.035 & $0.373^{* *}$ & & \\
\hline Mother's age & -0.027 & 0.010 & $-0.293^{\star *}$ & & \\
\hline Mother's regulation of emotions & -0.142 & 0.058 & $-0.245^{\star}$ & & \\
\hline
\end{tabular}

Notes. $-\mathrm{E}=$ negative emotion, $+\mathrm{E}=$ positive emotion, ${ }^{*} p<0.05,{ }^{* *} p<0.01$. 
The predictors of maternal emotion-related conversations were mother's level of education, age and ability to regulate their emotions. Model 2e explained 14\% of the variance of maternal emotion-related conversations (see Table 3). No significant result was obtained for maternal emotional terms.

Table 4 presents the results of significant predictors of paternal reactions and conversations. Regarding children's characteristics as predictors of paternal ERSBs, Model 1c showed that children's conscientiousness explained $8 \%$ of the variance the paternal punitive responses to the child's $-E$. Secondly, about fathers' characteristics as predictors of paternal ERSBs, Model 2a, including fathers' age and ability to communicate their emotions explained $6 \%$ of the variance of paternal encouragement of the child's $-\mathrm{E}$. The model $2 \mathrm{~d}$, including fathers' age and ability to regulate their emotions explained $10 \%$ of the variance of paternal minimizing responses to the child's $-\mathrm{E}$. Moreover, the model 1e, including fathers' ability to communicate their emotions and to regulate their emotions explained $6 \%$ of the variance of paternal discomfort to children's $+\mathrm{E}$. Finally, concerning the mutual influence of children's characteristics and fathers' characteristics as predictors of paternal ERSBs, Model 3b, including fathers' age, children's conscientiousness and chronological age explained 13\% of the variance of paternal distress to children's $-\mathrm{E}$.

No significant result was obtained for paternal comforting, problem-focused responses to children's $-\mathrm{E}$ and for paternal socialization, encouragement and reprimand to children's $+\mathrm{E}$.

The predictors for paternal emotion-related conversations were fathers' representations of emotions. The model if explained $5 \%$ of the variance of paternal emotion-related conversations. In addition, Model 2 g, including children's extraversion and fathers' age, explained $7 \%$ of the variance of paternal emotional terms (see Table 4).

It is important to note that our models were significant, but the percentages of variances explained were very low.

\section{Study 2: How do Parents' ERSBs and Children's Socio-Emotional Competences Interact?}

\subsection{Method}

\subsubsection{Participants and Procedure}

A subsample of participants of the Study 1 agreed to participate at this twowaves longitudinal study. A total of 53 two-parent families and their children (27 girls and 26 boys) participated. At Wave 1 (W1) (September-October), children were aged between 3 years and 4 months and 5 years and 10 months $(M=4.64$; $\mathrm{SD}=0.69)$ and the average age of mothers and fathers were 35.26 years $(\mathrm{SD}=$ $4.80)$ and 38.44 years $(\mathrm{SD}=5.45)$ respectively. The Wave 2 (W2) of this study occurred 6 months after W1 (March-April) during the same school year. As in the Study 1, children and their parents were recruited in French-speaking Belgian schools. The level of education of both parents is very high: in most cases either graduate school (37.7\% of mothers, $28.8 \%$ of fathers), or university (52.8\% 
Table 4. Predictors of paternal ERSBs.

\begin{tabular}{|c|c|c|c|c|c|}
\hline \multirow[b]{2}{*}{ Predictors } & \multicolumn{5}{|c|}{ Encouragement_-E } \\
\hline & $\mathrm{B}$ & $\mathrm{SE} / \mathrm{B}$ & $\beta$ & $R_{\text {odji }}^{2}$ & $F$ \\
\hline Model 1a & & & & 0.04 & $40.795^{\star}$ \\
\hline Father's age & 0.039 & 0.018 & 0.194 & & \\
\hline Model 2a & & & & 0.06 & $40.899^{* *}$ \\
\hline Father's age & 0.035 & 0.017 & 0.177 & & \\
\hline \multirow[t]{2}{*}{ Father's communication of emotions } & 0.259 & 0.118 & 0.193 & & \\
\hline & \multicolumn{5}{|c|}{ Distress_-E } \\
\hline Predictors & B & $\mathrm{SE} / \mathrm{B}$ & $\beta$ & $R_{a d i j}^{2}$ & $F$ \\
\hline Model 1b & & & & 0.08 & $110.939^{* *}$ \\
\hline Father's age & -0.048 & 0.014 & $-0.297^{\star *}$ & & \\
\hline Model 2b & & & & 0.10 & $80.097^{* * *}$ \\
\hline Father's age & -0.048 & 0.014 & $-0.296^{\star *}$ & & \\
\hline Child's conscientiousness & -0.091 & 0.046 & $-0.169^{*}$ & & \\
\hline Model 3b & & & & 0.13 & $70.335^{\star * *}$ \\
\hline Father's age & -0.051 & 0.014 & $-0.314^{* * *}$ & & \\
\hline Child's conscientiousness & -0.109 & 0.046 & $-0.202^{*}$ & & \\
\hline \multirow[t]{2}{*}{ Child's age } & 0.017 & 0.008 & $0.195^{*}$ & & \\
\hline & \multicolumn{5}{|c|}{ Punitive_-E } \\
\hline Predictors & B & $\mathrm{SE} / \mathrm{B}$ & $\beta$ & $R_{\text {odij }}^{2}$ & $F$ \\
\hline Model 1c & & & & 0.08 & $110.804^{*}$ \\
\hline \multirow[t]{2}{*}{ Child's conscientiousness } & -0.158 & 0.046 & -0.296 & & * \\
\hline & \multicolumn{5}{|c|}{ Minimizing responses_-E } \\
\hline Predictors & B & $\mathrm{SE} / \mathrm{B}$ & $\beta$ & $R_{\text {adjj }}^{2}$ & $F$ \\
\hline Model 1d & & & & 0.06 & 90.196 \\
\hline Father's age & -0.050 & 0.017 & $-0.264^{* *}$ & & $* *$ \\
\hline Model 2d & & & & 0.10 & \\
\hline Father's age & -0.046 & 0.016 & $-0.239^{* *}$ & & 70.973 \\
\hline \multirow[t]{2}{*}{ Father's regulation of emotions } & 0.360 & 0.143 & $0.216^{*}$ & & $* *$ \\
\hline & \multicolumn{5}{|c|}{ Discomfort_+E } \\
\hline Predictors & $\mathrm{B}$ & $\mathrm{SE} / \mathrm{B}$ & $\beta$ & $R_{\text {odji }}^{2}$ & $F$ \\
\hline Model 1e & & & & 0.06 & 40.855 \\
\hline Father's communication of emotions Fa & -0.356 & 0.138 & -0.228 & & $* *$ \\
\hline \multirow[t]{2}{*}{ ther's regulation of emotions } & -0.381 & 0.178 & -0.189 & & \\
\hline & \multicolumn{5}{|c|}{ Emotion-related conversation } \\
\hline Predictors & B & $\mathrm{SE} / \mathrm{B}$ & $\beta$ & $R_{\text {atij }}^{2}$ & $F$ \\
\hline Model 1f & & & & 0.05 & 70.285 \\
\hline \multirow[t]{2}{*}{ Father's representations of emotions } & 0.153 & 0.057 & 0.236 & & $* *$ \\
\hline & \multicolumn{5}{|c|}{ Emotional terms } \\
\hline Predictors & B & $\mathrm{SE} / \mathrm{B}$ & $\beta$ & $R_{\text {adji }}^{2}$ & $F$ \\
\hline Model 1g & & & & 0.03 & $40195 *$ \\
\hline Child's extraversion & 0.925 & 0.452 & $0.185^{\star}$ & & 70.130 \\
\hline Model $2 \mathrm{~g}$ & & & & 0.07 & \\
\hline Child's extraversion & 0.893 & 0.443 & $0.176^{\star}$ & & 50.867 \\
\hline Father's age & 0.260 & 0.107 & $0.214^{*}$ & & * \\
\hline
\end{tabular}

Notes: $-\mathrm{E}=$ negative emotion, $+\mathrm{E}=$ positive emotion, ${ }^{*} p<0.05,{ }^{* *} p<0.01,{ }^{* *} p<0.001$. 
of mothers, $48.1 \%$ of fathers). Families were predominantly Caucasian and the majority of children lived with both their biological parents (97.2\%).

Families were informed about the research project by their children's school. For the two waves of data collection, the teachers gave parents an information letter about the project and consent forms for their participation. When they had signed the consent form, they received the questionnaires and the testing with the child started. Children were tested at school by experienced psychology researchers or by trained psychology students. After their participation, parents received a brief report including observations and results of their child's assessment. The parents were informed that all data would be kept anonymous and that they could withdraw from the study at any time.

\subsubsection{Measures}

\section{1) Assessment of children's ToM abilities}

ToM-emotions tasks [41]. Three tasks are proposed to children to assess their understanding of emotions. The first preliminary task assesses the prerequisite of recognition of the four targeted emotions (joy, sadness, anger and fear). A success is needed to administer the following two ToM tasks. The second task evaluates children's understanding of the causes of emotions. Four stories were told to the child in which a protagonist feel an emotion that vary according to the situation with which he or she was confronted. The third task assesses children's understanding of the consequences of emotions. Four scenarios were presented to the child presenting an emotional situation. For each story, the child was asked to select the protagonist's behaviour to finish the story, by selecting one of three pictures (an adjusted social behaviour, a maladjusted social behaviour or a neutral behaviour). For these two tasks, the response to each emotional scenario was scored between 0 and 1.5 points according to the participant's responses. The maximum score was 6 points by task.

The validation results revealed a very good inter-rater reliability $(r=0.96 ; p<$ 0.01 ). Cohen's kappa averaged 0.92 and the test-retest stability (with an interval of 2 months) was excellent (0.99 and 0.98).

ToM-beliefs tasks [41]. Five tasks are proposed to children to assess their understanding of beliefs and false beliefs. The First task (The deception skills test, [42]) assesses the child's ability to trick the experimenter by hidden an object in front of him. The second task (The change of representation task, [43]) evaluates whether or not the child was able to adopt the visual perspective of an adult sitting opposite him or her. The third task (The appearance-reality task, [44]) assesses the child's ability to distinguish the reality from the appearance of an object (for example, a candle looking like a flower). The fourth task (The unexpected content task, [45]) evaluates whether or not the child was able to understand that he or she had been tricked by the experimenter about the contents of a prototypical box (a Smarties box that contained pencils), as well as to understand that other people can be tricked in the same way. Finally, the fifth task (The change of location task, [46]) assesses the child's ability to predict a doll's behaviour given the doll's false belief. The story concerned a doll who believed 
that a desirable object (chocolate) was in one location when, as the child knew, it was actually in another location. Each task was scored out of one point.

For the validation of this tool, the inter-rater percentage validation was between 99\% and 100\%, Cohen's Kappa was between 0.98 and 0.99, and the Pearson correlation coefficient (inter-judges) was between 0.99 and 1. No difference between the test and retest session was observed.

Theory of Mind Task Battery ([47] French version, [48]). This measure assesses children's ToM abilities by 15 test questions allocated in 9 tasks. These tasks evaluates isolated mental states and also combination of mental states (e.g. desire-based emotions).

The validation of the French version revealed a Cronbach's alpha of 0.75 and a coefficient of test-retest stability of $0.87(p<0.001)$.

Theory of Mind Inventory (ToMI, [49]; French version, [50]). This questionnaire assesses caregivers' perceptions of children's ToM abilities. The ToMI is appropriate for children aged between 2 and 17 years old, and is designed to identify caregivers' views about children's thoughts and feelings. The questionnaire consists of 39 statements (e.g. 'My child understands that people can lie to purposely mislead others') about the nine mental states related to ToM. One of the parents (mostly mothers) indicates the degree of agreement with each item by placing the appropriate vertical mark along a continuum ranging from 0 (definitely not) to 20 (definitely).

The validation of the French version matched that of the original version. The Cronbach's alpha was 0.94 , and the coefficient of test-retest stability was very significant $(r=0.86, p<0.001)$.

Factor ToM. We used a factorial analysis in principal components forced to one factor to aggregate direct and indirect ToM measures. At W1, the saturation of measures on this factor ranged from 0.596 to 0.815 , and it accounted for $55.57 \%$ of the variance. The Cronbach's alpha was 0.70 . At W2, it explained $49.49 \%$ of the variance, and the saturations ranged from 0.601 to 0.738 . The Cronbach's alpha was 0.60 .

2) Assessment of children's emotional regulation

Emotion Regulation Checklist (ERC, [51]; French version, [52]). This questionnaire evaluates teachers' perception of children's emotion regulation and emotionality. It consists of 24 items rated on a 4-point scale that indicate the frequency of emotion-related behaviors from 1 (never) to 4 (always). Two subscales compose this measure: The Emotion Regulation subscale, which describes appropriate empathy, affective displays and emotional understanding, and the Lability/Negativity subscale, which reflects behaviour including mood lability, angry reactivity and dysregulated negative affect. For each subscale, an average score $(\max =4)$ can be calculated and a composite score of emotion regulation can be created by taking into account the scores in both subscales. In this study, we used the composite score.

The French validation of this questionnaire matched those for the original version and revealed high internal consistency, with Cronbach's alpha values for the 
Lability/Negativity subscale of 0.82 and for the Emotion Regulation subscale of 0.72 .

3) Assessment of children's social adjustment

Social adjustment scales (EASE, [53]). This measure assesses adult's perceptions of children's social adjustment. This questionnaire, inspired from conceptions of ToM in the social development, integrates both items regarding the child's abilities to take into account mental states in social relationships (ToM) and items about the child's abilities to display social skills (No ToM). In this study, parents (mostly mothers) and teachers filled in the questionnaire independently. The adult indicates for each item if the behavior is usual for their child.

The validation of this questionnaire revealed that the two subscales have a good internal consistency; the Cronbach's alpha for the "ToM subscale" is 0.77 , and it is 0.79 for the "No ToM subscale".

Factor social adjustment. We applied a factorial analysis in principal components forced to one factor to aggregate teachers' and parents' scores. At W1, the saturation of measures on this factor ranged from 0.701 to 0.800 , and it accounted for $59.41 \%$ of the variance. The Cronbach's alpha was 0.76 . At W2, it explained $65.89 \%$ of the variance, and the saturations ranged from 0.751 to 0.839. The Cronbach's alpha was 0.82 .

\section{4) Assessment of parental ERSBs}

Parental Reactions toward Positive and Negative Emotions [34] as described in Study 1.

Questionnaire of Parent-Child Conversations about Emotions (QPCCE, [37]) as described in Study 1.

\subsection{Results}

\subsubsection{Data Analysis}

First, descriptive statistics analyses for all variables at W1 and W2 and inter-correlation, using Pearson correlation analysis, between parents' ERSBs at W1 and children's socio-emotional competences at W2 and between children's socio-emotional competences at W1 and parents' ERSBs at W2 have been applied. Secondly, to observe the stability of targeted variables between $\mathrm{W} 1$ and W2, Paired-sample t-tests were conducted. Finally, predictive links between our two times of measure have been explored by linear regression analyses by the stepwise method. For this objective, mothers and fathers have been analysed independently to observe distinct effects. Moreover, two-way interaction terms were used to explore the interaction between parents' ERSBs and children's socio-emotional competences. To maximise interpretability and to minimize problems of multicollinearity, scores for each of the predictor variables were centered (raw score minus the mean) [54]. As in previous studies [2] [7] [12] conducted with a small sample, the use of multiple linear regression was evaluated as a good method in light of the objectives of the Study 2.

\subsubsection{Preliminary Analyses}

Table 5 and Table 6 showed descriptives statistics (means and standard deviation) and inter-correlation for children's socio-emotional competences measures 
Table 5. Paired-sample $t$-test between W1 and W2.

\begin{tabular}{|c|c|c|c|c|c|}
\hline & \multicolumn{2}{|c|}{ W1 } & \multicolumn{2}{|c|}{ W2 } & \multirow{2}{*}{$\begin{array}{c}t \text {-test } \\
d f(52)\end{array}$} \\
\hline & $M$ & $\mathrm{SD}$ & $M$ & $\mathrm{SD}$ & \\
\hline \multicolumn{6}{|l|}{ Children's socio-emotional competences } \\
\hline Factor ToM & 0.00 & 10.00 & -0.014 & 10.00 & -0.165 \\
\hline ERC-composite score ER $(\mathrm{Max}=8)$ & 60.39 & 0.58 & 60.47 & 0.65 & 0.826 \\
\hline Factor social adjustment & -0.03 & 10.02 & -0.002 & 10.00 & 0.207 \\
\hline \multicolumn{6}{|l|}{ Maternal ERSBs } \\
\hline Supportive reactions_-E $(\mathrm{Max}=7)$ & 50.12 & 0.80 & 50.17 & 0.74 & 0.600 \\
\hline Non-supportive reactions_-E $(\operatorname{Max}=7)$ & 20.72 & 0.70 & 20.78 & 0.77 & 0.941 \\
\hline Supportive reactions_+E $(\operatorname{Max}=7)$ & 50.32 & 0.68 & 50.13 & 0.85 & -10.662 \\
\hline Non-supportive reactions_+E $(\operatorname{Max}=7)$ & 30.23 & 0.92 & 30.23 & 10.20 & -0.010 \\
\hline Emotion-related conversations $(\mathrm{Max}=4)$ & 20.57 & 0.37 & 20.56 & 0.44 & -0.044 \\
\hline Emotional terms & 120.18 & 60.21 & 140.43 & 70.51 & $20.699 * *$ \\
\hline \multicolumn{6}{|l|}{ Paternal ERSBs } \\
\hline Supportive reactions_-E $(\operatorname{Max}=7)$ & 40.96 & 0.61 & 40.85 & 0.76 & -10.117 \\
\hline Non-supportive reactions_-E $(\operatorname{Max}=7)$ & 30.19 & 0.64 & 30.25 & 0.61 & 0.838 \\
\hline Supportive reactions_+E $(\operatorname{Max}=7)$ & 50.38 & 0.75 & 50.13 & 0.83 & -10.744 \\
\hline Non-supportive reactions_+E $(\operatorname{Max}=7)$ & 30.27 & 10.02 & 30.36 & 10.07 & 0.543 \\
\hline Emotion-related conversations $(\mathrm{Max}=4)$ & 20.33 & 0.39 & 20.31 & 0.37 & -0.266 \\
\hline Emotional terms & 110.40 & 50.84 & 120.56 & 70.93 & 10.413 \\
\hline
\end{tabular}

Notes. $M=$ mean, $\mathrm{SD}=$ standard deviation, $\mathrm{W}=$ Wave, ToM $=$ Theory of Mind, ToMI = Theory of Mind Inventory, $\mathrm{ERC}=$ Emotion Regulation Checklist, $\mathrm{EASE}=$ social adjustment scales, ERSBs $=$ Emotion Related Socialization Behaviours, $-\mathrm{E}=$ negative emotion, $+\mathrm{E}=$ positive emotion, ${ }^{* *} p<0.01$.

and for parents' ERSBs measures for the two waves of data collection. The Paired-sample t-tests revealed no significant differences between W1 and W2 in children's scores (see Table 5). Concerning parents' ERSBs, results indicated that these behaviours are relatively stable except for maternal emotional terms. Indeed, mothers tend to increase the number of emotional terms that they used during emotion-related conversations when their children grow up.

\subsubsection{Predicting W2 Children's Socio-Emotional Competences from W1 Parents' ERSBs}

For the purpose of control the predicting effect of children's socio-emotional competences at W1, we entered these variables in Step 1 in each model. In Step 2, we added parents' ERSBs (reactions to children's emotions, emotion-related conversations, emotional terms) displayed at $\mathrm{W} 1$ and the two-way interaction terms were added in Step 3. We present here only significant model for which predictors added in Step 2 or Step 3 were significant.

Concerning maternal model, as shown in Table 7, the model was significant for children's ToM at W2. Children's ToM at W1 entered in Step 1 was significant 
Table 6. Correlations among Study 2 variables.

\begin{tabular}{|c|c|c|c|c|c|c|c|c|c|c|c|c|c|c|c|}
\hline \multirow{2}{*}{ W1 } & \multicolumn{15}{|c|}{ W2 } \\
\hline & 1 & 2 & 3 & 4 & 5 & 6 & 7 & 8 & 9 & 10 & 11 & 12 & 13 & 14 & 15 \\
\hline \multirow{2}{*}{\multicolumn{16}{|c|}{$\begin{array}{l}\text { Children's } \\
\text { socio-emotional } \\
\text { competences }\end{array}$}} \\
\hline & & & & & & & & & & & & & & & \\
\hline 1) Factor ToM & $0.814^{* * *}$ & 0.030 & $548^{* *}$ & -0.026 & -0.179 & -0.187 & -0.182 & 0.083 & 0.212 & -0.227 & 0.164 & $-0.322^{*}$ & -0.143 & 0.176 & 0.156 \\
\hline $\begin{array}{l}\text { 3) Factor social } \\
\text { adjustment }\end{array}$ & $0.397^{\star *}$ & -0.018 & $0.622^{* * *}$ & -0.011 & -0.187 & -0.091 & -0.105 & -0.081 & 0.065 & -0.244 & -0.159 & $-0.377^{\star *}$ & -0.229 & 0.063 & 0.139 \\
\hline \multicolumn{16}{|l|}{ Maternal ERSBs } \\
\hline $\begin{array}{l}\text { 4) Supportive } \\
\text { reactions_-E }\end{array}$ & -0.033 & 0.000 & 0.058 & $0.651^{\star *}$ & -0.063 & 0.191 & 0.036 & 0.003 & -0.182 & 0.079 & $-0.285^{\star}$ & 0.057 & -0.057 & -0.133 & -0.178 \\
\hline $\begin{array}{l}\text { 6) Supportive } \\
\text { reactions_+E }\end{array}$ & 0.013 & 0.006 & 0.100 & 0.255 & 0.013 & $0.466^{* *}$ & -0.082 & -0.028 & 0.150 & -0.034 & 0.124 & -0.098 & 0.166 & -0.087 & 0.155 \\
\hline $\begin{array}{l}\text { 7) Non-supportive } \\
\text { reactions_+E }\end{array}$ & -0.131 & 0.035 & 0.014 & -0.074 & 0.159 & -0.092 & $0.387^{\star *}$ & 0.231 & 0.028 & 0.043 & 0.018 & 0.015 & 0.003 & -0.056 & -0.154 \\
\hline $\begin{array}{l}\text { 8) Emotion-related } \\
\text { conversations }\end{array}$ & 0.032 & 0.138 & 0.245 & 0.147 & -0.002 & 0.145 & 0.092 & $0.586^{\star * *}$ & 0.187 & 0.189 & -0.146 & 0.168 & 0.017 & 0.118 & 0.155 \\
\hline 9) Emotional terms & 0.152 & 0.129 & 0.220 & -0.021 & -0.221 & -0.081 & -0.109 & 0.083 & $0.636^{* * *}$ & -0.270 & 0.262 & -0.168 & 0.167 & -0.012 & $0.457^{\star *}$ \\
\hline \multicolumn{16}{|l|}{ Paternal ERSBs } \\
\hline $\begin{array}{l}\text { 10) Supportive } \\
\text { reactions_-E }\end{array}$ & -0.168 & 0.135 & -0.178 & 0.105 & -0.082 & -0.049 & -0.033 & -0.119 & 0.121 & $0.444^{* *}$ & 0.092 & 0.213 & 0.194 & 0.238 & 0.091 \\
\hline $\begin{array}{l}\text { 11) Non-supportive } \\
\text { reactions_-E }\end{array}$ & 0.146 & 0.003 & 0.005 & -0.190 & 0.176 & 0.023 & 0.001 & 0.026 & $0.371^{\star *}$ & -0.071 & $0.590^{* * *}$ & -0.136 & 0.209 & 0.148 & 0.227 \\
\hline $\begin{array}{l}\text { 12) Supportive } \\
\text { reactions_+E }\end{array}$ & -0.105 & 0.085 & -0.199 & -0.038 & -0.015 & 0.121 & -0.073 & 0.169 & $0.309^{*}$ & 0.107 & 0.171 & 0.165 & 0.092 & -0.095 & 0.169 \\
\hline $\begin{array}{l}\text { 14) Emotion-related } \\
\text { conversations }\end{array}$ & 0.059 & 0.137 & -0.008 & 0.159 & 0.152 & 0.019 & -0.059 & -0.027 & 0.072 & 0.156 & 0.011 & 0.044 & -0.169 & $0.486^{* * *}$ & 0.077 \\
\hline 15) Emotional terms & 0.086 & 0.152 & 0.165 & 0.167 & -0.026 & 0.095 & 0.092 & -0.018 & $0.454^{\star *}$ & -0.024 & 0.067 & -0.226 & 0.249 & 0.017 & $0.732^{* * *}$ \\
\hline
\end{tabular}

Notes. $\mathrm{W}=\mathrm{Wave}, \mathrm{ToM}=$ Theory of Mind, $\mathrm{ERC}=$ Emotion Regulation Checklist, ERSBs $=$ Emotion Related Socialization Behaviours, $-\mathrm{E}=$ negative emotion, $+\mathrm{E}=$ positive emotion, ${ }^{*} p<0.05,{ }^{* *} p<0.01,{ }^{* *} p<0.001$.

and accounted for $65 \%$ of the variance. Moreover, the two-way interaction terms between maternal emotion-related conversations at W1 and children's ToM at $\mathrm{W} 1$ added in Step 3 accounted for an additional 3\% of the variance in the score of children's ToM at W2. To better interpret this significant two-way interaction, we conducted follow-up analyses. We plotted the association between children's ToM at W2 and maternal emotion-related conversation at W1 at low, moderate and high levels of children's ToM at W1. Moreover, simple slope analyses (using the PROCESS tool by Andrew Hayes, [55]) were conducted. The simple slope analyses (see Figure 2) revealed that maternal emotion-related conversations display at W1 predict positively children's ToM at W2 for children with a low level of ToM at W1, and this slope was marginally $\operatorname{significant}(\beta=0.6116, p<$ $0.10)$. However, maternal emotion-related conversations display at W1 predict negatively children's ToM at W2 for children with a high level of ToM at W1 ( $\beta$ $=-0.5845, p<0.05)$. We also estimated the regions of significance with the Johnson-Neyman method [56]. 
Table 7. Summary of regression statistics predicting children's socio-emotional competences at Wave 2.

\begin{tabular}{|c|c|c|c|c|c|c|c|c|c|c|c|}
\hline \multirow[b]{2}{*}{ Maternal ERSBs W1 } & \multicolumn{11}{|c|}{ Children's socio-emotional competences W2 } \\
\hline & \multicolumn{5}{|c|}{ Factor ToM } & \multicolumn{2}{|l|}{ Paternal ERSBs W1 } & \multicolumn{3}{|c|}{ Composite score ER } & \multirow[b]{2}{*}{$F$} \\
\hline Predictors & $B$ & $S E / B$ & $\beta$ & $R_{a d j i j}^{2}$ & $F$ & Predictors & $B$ & $\mathrm{SE} / \mathrm{B}$ & $\beta$ & $R_{a d j j}^{2}$ & \\
\hline Model M1a & & & & 0.65 & $97.956^{\star * *}$ & Model F1a & & & & 0.17 & $11.528^{\star \star}$ \\
\hline Factor ToM & 0.817 & 0.083 & $0.814^{* * *}$ & & & Composite score ER & 0.474 & 0.140 & $0.433^{* *}$ & & \\
\hline Model M2a & & & & 0.68 & $5.424^{*}$ & Model F2a & & & & 0.22 & $4.377^{\star}$ \\
\hline Factor ToM & 0.804 & 0.079 & $0.801^{* * *}$ & & & Composite score ER & 0.508 & 0.136 & $0.463^{* * *}$ & & \\
\hline $\begin{array}{c}\text { Emotion-related } \\
\text { conversations } \times \\
\text { Factor ToM }\end{array}$ & -0.598 & 0.257 & $-0.184^{*}$ & & & $\begin{array}{c}\text { Emotion-related } \\
\text { conversations } \times \\
\text { composite score ER }\end{array}$ & 0.832 & 0.398 & $0.260^{*}$ & & \\
\hline \multicolumn{12}{|c|}{ Factor Social adjustment } \\
\hline Predictors & $B$ & $S E / B$ & $\beta$ & $R_{o d j i j}^{2}$ & $F$ & & & & & & \\
\hline Model M1b & & & & 0.37 & $26.473^{* * *}$ & & & & & & \\
\hline Factor Social adjustment & 0.609 & 0.118 & $00.622^{* * *}$ & & & & & & & & \\
\hline Model M2b & & & & 0.42 & $4.485^{\star}$ & & & & & & \\
\hline Factor Social adjustment & 0.686 & 0.119 & $0.700^{* * *}$ & & & & & & & & \\
\hline $\begin{array}{l}\text { Non-supportive } \\
\text { reactions_+E }\end{array}$ & 0.295 & 0.139 & $0.258^{*}$ & & & & & & & & \\
\hline Model M1c & & & & 0.37 & $26.473^{\star * *}$ & & & & & & \\
\hline Factor Social adjustment & 0.609 & 0.118 & $0.622^{* * *}$ & & & & & & & & \\
\hline Model M2c & & & & 0.42 & $4.425^{*}$ & & & & & & \\
\hline Factor Social adjustment & 0.600 & 0.114 & $0.612^{\star * *}$ & & & & & & & & \\
\hline $\begin{array}{c}\text { Emotion-related } \\
\text { conversations }\end{array}$ & 0.628 & 0.299 & $0.245^{\star}$ & & & & & & & & \\
\hline
\end{tabular}

Notes. $\mathrm{W}=$ Wave, $\mathrm{ERSB} s=$ Emotion Related Socialization Behaviours, ToM $=$ Theory of Mind, ER = Emotion Regulation, $+\mathrm{E}=$ positive emotion, ${ }^{*} p<0.05$, ${ }^{* *} p<0.01,{ }^{* * *} p<0.001$.

The results indicated that the association between children's ToM at W2 and maternal emotion-related conversation at W1 was significant $(p<0.05)$ when children's ToM at W1 (centered score, $M=0, \mathrm{SD}=1.00$ ) was within the range from -2.15 to -1.58 and from 0.86 to 1.65 .

Moreover, the model was significant for children's social adjustment at W2. Children's social adjustment at W1 entered in Step 1 was significant and accounted for $37 \%$ of the variance. Model M2b showed that maternal non-supportive reactions to children's positive emotion display at W1 added in Step 2 accounted for an additional $5 \%$ of the variance in the score of children's social adjustment at W2. Model M2c showed that maternal emotion-related conversations display at W1 added in Step 2 accounted for an additional 5\% of the variance in the score of children's social adjustment at W2. There are no significant results for children's ER at W2. 


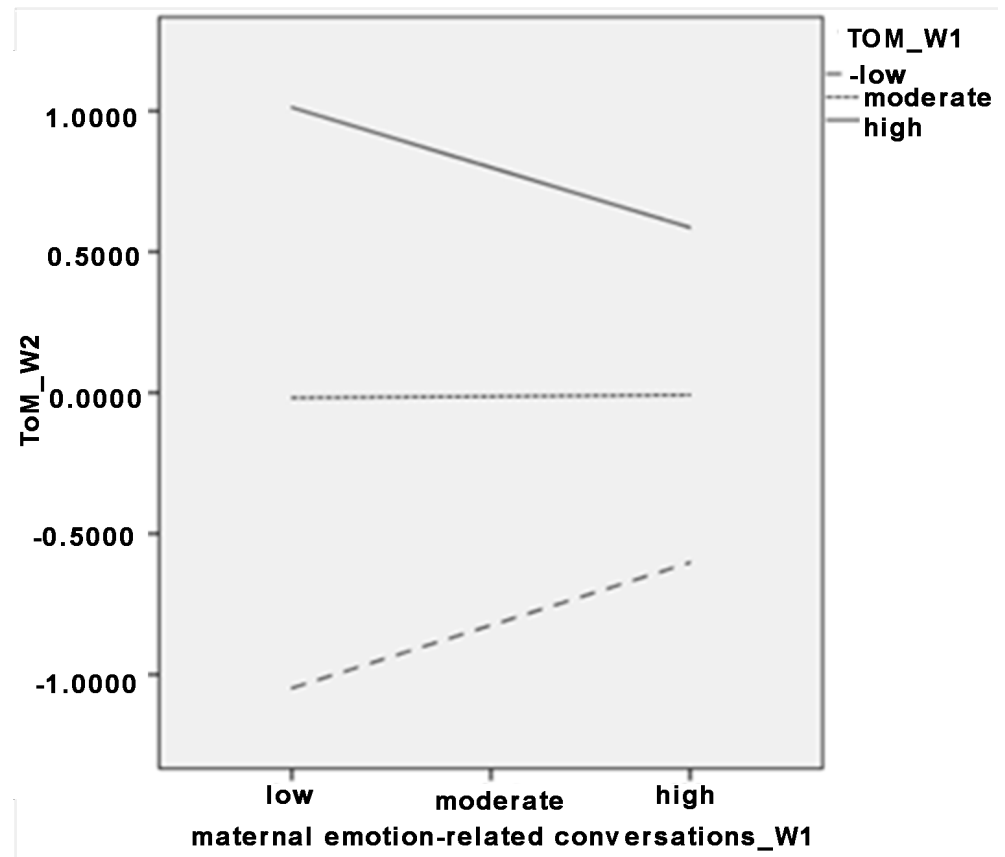

Figure 2. Association between children's ToM competences at W2 and maternal emotion-related conversation at $\mathrm{W} 1$ as a function of high, moderate, and low levels of children's ToM competences at W1.

Concerning paternal model, as shown in Table 7, the model was significant for children's ER competences at W2. Children's ER at W1 entered in Step 1 was significant and accounted for $17 \%$ of the variance. Moreover, the two-way interaction terms between paternal emotion-related conversations at $\mathrm{W} 1$ and children's ER at W1 added in Step 3 accounted for an additional 5\% of the variance in the score of children's ER at W2. To better interpret this significant two-way interaction, analyses similar to those applied for the maternal model were conducted. We plotted the association between children's ER at W2 and paternal emotion-related conversation at W1 at low, moderate and high levels of children's ER at W1. Moreover, simple slope analyses were conducted and showed that paternal emotion-related conversations display at W1 predict positively children's ER competences at W2 for children with a high level of ER competences at W1(see Figure 3), and this slope was significant $(\beta=0.5864, p<0.05)$. Further, in estimating the regions of significance, we found that the association between children's ER at W2 and paternal emotion-related conversation at W1 was significant $(p<0.05)$ when children's ER at W1 (centered score, $M=0$, SD $=0.59$ ) was within the range from .86 to -1.22 . There are no significant results for children's ToM and social adjustment at W2.

\subsubsection{Predicting W2 Parents' ERSBs from W1 Children's Socio-Emotional Competences}

For the purpose of control the predicting effect of parents' ERSBs display at W1, we entered these variables in Step 1 in each model. In Step 2, we added children's socio-emotional competences at W1 and the two-way interaction terms 


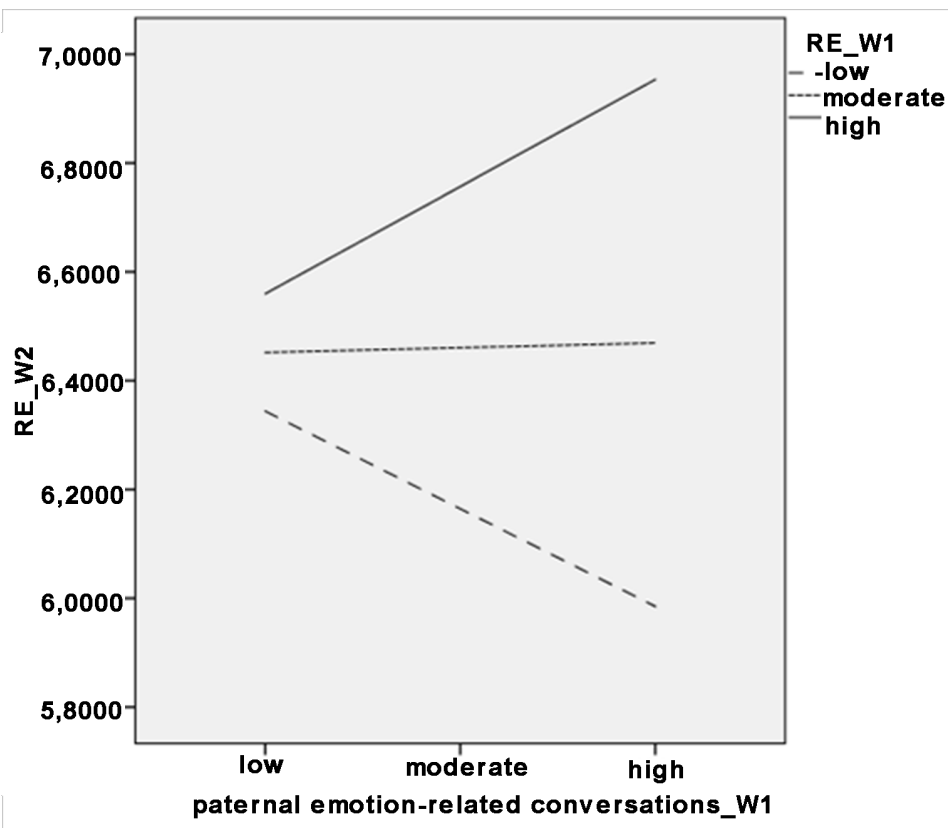

Figure 3. Association between children's ER competences at W2 and paternal emotion-related conversation at W1 as a function of high, moderate, and low levels of children's ER competences at W1.

were added in Step 3. We present here only significant model for which predictors added in Step 2 or Step 3 were significant.

There are no significant result for maternal model. About paternal model, as shown in Table 8, the model was significant for paternal supportive reactions to children's positive emotions display at W2. Children's ToM at W1 entered in Step 2 was significant and accounted for $9 \%$ of the variance. Moreover, another model revealed that children's social adjustment at W1 explained 14\% of the variance. Finally, a two-way interaction terms between children's ER at W1 and paternal supportive reactions to children's positive emotions display at W1 explained $7 \%$ of the variance. Similar analyses than previously were conducted to better interpret this significant two-way interaction. We plotted the association between paternal supportive reactions to children's positive emotions display at W2 and children's ER at W1 at low, moderate and high levels of paternal supportive reactions to children's positive emotions display at W1. The simple slope analyses (see Figure 4) showed that children's ER at W1 predict positively paternal supportive reactions to children's positive emotions display at W2 for father with a low level of supportive reactions to children's positive emotions ( $\beta=$ $0.4518, \mathrm{p}<0.05)$. The estimation of the region of significance indicated that the association between paternal supportive reactions to children's positive emotions display at W2 and children's ER was significant $(\mathrm{p}<0.05)$ when paternal supportive reactions to children's positive emotions display at W1 (centered score, $\mathrm{M}=0, \mathrm{SD}=0.75$ ) was within the range from -1.6277 to -0.7277 . We obtained also a significant model for paternal non-supportive reactions to children's negative emotions display at W2. Paternal non-supportive reactions to 
Table 8. Summary of regression statistics predicting paternal ERSBs at Wave 2.

\begin{tabular}{|c|c|c|c|c|c|}
\hline & \multicolumn{5}{|c|}{ Paternal ERSBs W2 } \\
\hline Children's socio-emotional competences W1 & \multicolumn{5}{|c|}{ Supportive_+E } \\
\hline Predictors & $B$ & $S E / B$ & $\beta$ & $R_{\text {adj }}^{2}$ & $F$ \\
\hline Model F1a & & & & 0.09 & $5.804^{*}$ \\
\hline Factor ToM & -0.270 & 0.112 & $-0.322^{\star}$ & & \\
\hline $\begin{array}{l}\text { Model F1b } \\
\text { Factor Social adjustment }\end{array}$ & -0.322 & 0.117 & $-0.377^{\star *}$ & 0.14 & $7.613^{* *}$ \\
\hline Model F1c & & & & 0.07 & $5.005^{*}$ \\
\hline \multirow[t]{2}{*}{ ERX Supportive reactions_+E } & -0.566 & 0.253 & $-0.299^{*}$ & & \\
\hline & \multicolumn{5}{|c|}{ Non-supportive_-E } \\
\hline Predictors & $B$ & $S E / B$ & $\beta$ & $R_{a d j j}^{2} j$ & $F$ \\
\hline Model F1c & & & & 0.33 & $27.216^{* * *}$ \\
\hline Non-supportive reactions_-E & 0.559 & 0.107 & $0.590^{\star * *}$ & & \\
\hline Model F2c & & & & 0.38 & 4.373 \\
\hline Non-supportive reactions_-E & 0.565 & 0.104 & $0.597^{\star * *}$ & & \\
\hline ERXNon-supportive reactions_-E & -0.376 & 0.180 & $-0.229^{*}$ & & \\
\hline
\end{tabular}

Notes. $\mathrm{W}=$ Wave, $\mathrm{ERSB}$ = Emotion Related Socialization Behaviours, ToM $=$ Theory of Mind, ER = Emotion Regulation, $-\mathrm{E}=$ negative emotion, $+\mathrm{E}=$ positive emotion, ${ }^{*} p<0.05,{ }^{* *} p<0.01,{ }^{* *} p<0.001$.

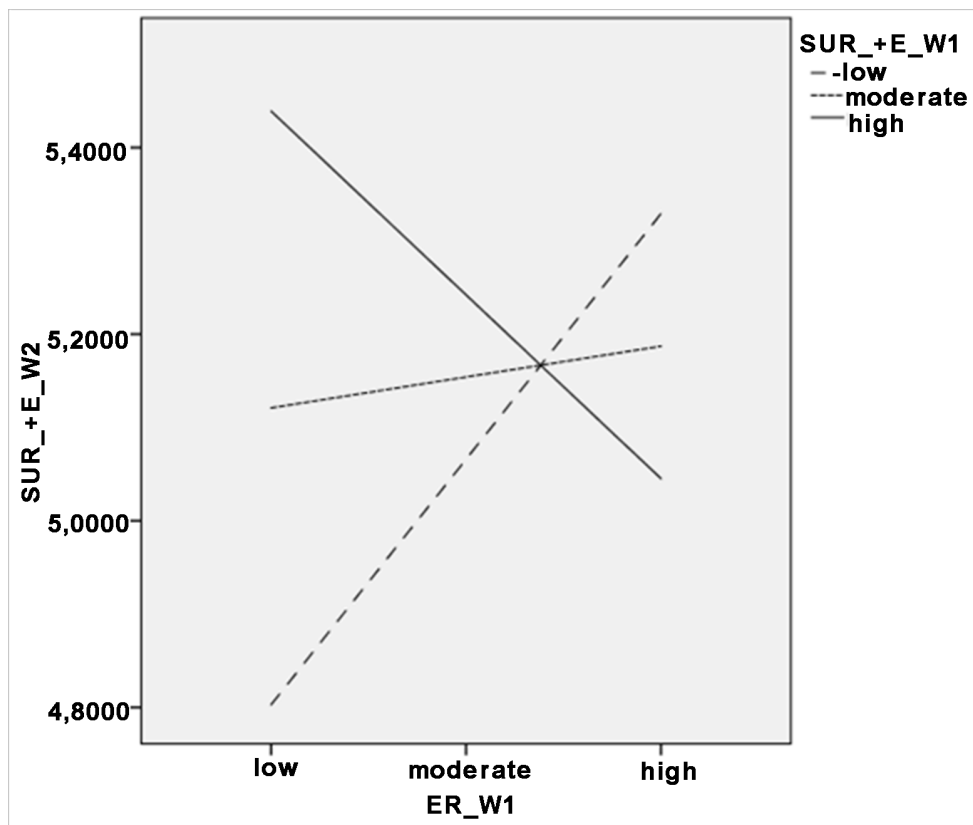

Figure 4. Association between paternal SUR to children's positive emotions at W2 and children's ER at W1 as a function of high, moderate, and low levels of paternal SUR to children's positive emotions at W1.

children's negative emotions display at W1 entered in Step 1 explained 33\% of the variance. Moreover, the two-way interaction terms between children's ER at W1 and paternal non-supportive reactions to children's negative emotions dis- 
play at W1 accounted for an additional 5\% of the variance. As shown by the simple slope analyses (see Figure 5), children's ER at W1 predict positively paternal non-supportive reactions to children's negative emotions display at W2 for father with a low level of non-supportive reactions to children's negative emotions $(\beta=0.3293, \mathrm{p}<0.05)$. The estimation of the region of significance indicated that the association between paternal non-supportive reactions to children's negative emotions display at W2 and children's ER was significant ( $\mathrm{p}<$ $0.05)$ when paternal non-supportive reactions to children's negative emotions display at $\mathrm{W} 1$ (centered score, $\mathrm{M}=0, \mathrm{SD}=0.64$ ) was within the range from -1.3382 to -0.5294 .

\section{Discussion}

Preschool period is a critical period in children's socio-emotional development because they have to adapt to a new social environment. Children become able to understand their own mental states and those of others, to take other's perspective, to better regulate their emotions according to the situation and to adjust behaviours during social interactions. These abilities develop through their social interactions, notably within the family context. These current studies investigated maternal and paternal ERSBs - the way in which parents react to their children's emotions and the way in which they discuss about emotions with their children-by exploring the determinants of these behaviours and the predictive links with children's socio-emotional competences. Although previous studies provided information about this socialization process, our studies has provided new data by including fathers and by using a short-term longitudinal design in

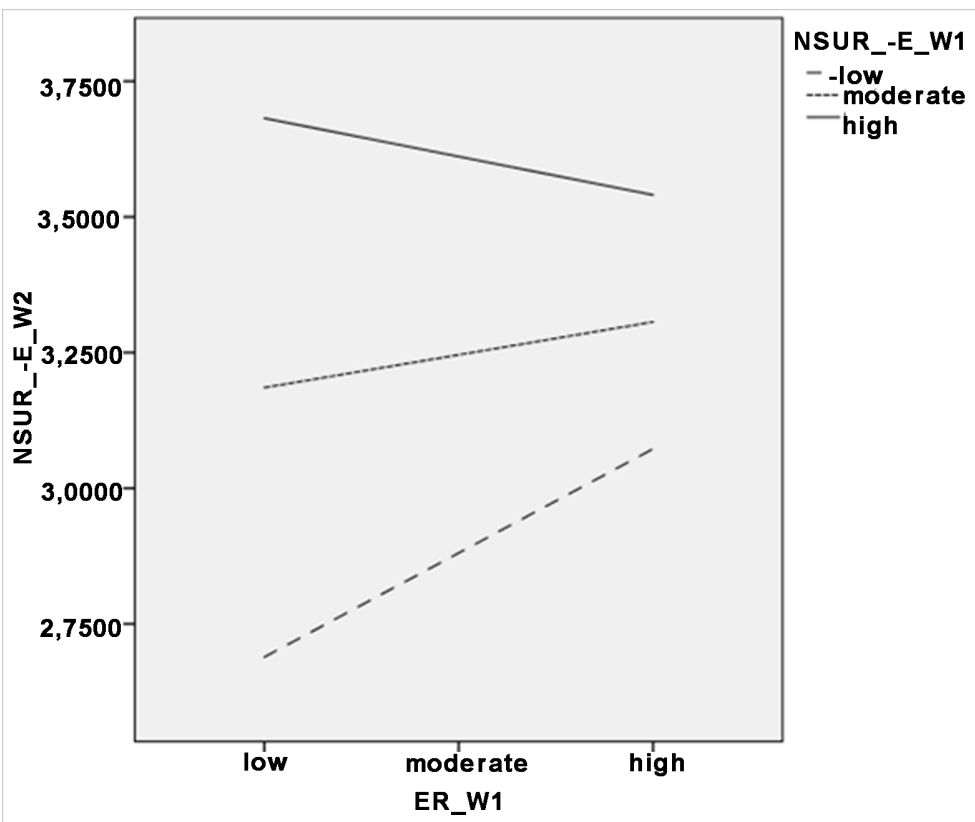

Figure 5. Association between paternal NSUR to children's negative emotions at W2 and children's ER at W1 as a function of high, moderate, and low levels of paternal NSUR to children's negative emotions at W1. 
order to observe also the influence of children's socio-emotional competences on parents' ERSBs.

Study 1 analyses the variability of maternal and paternal ERSBs according to parents' and children's characteristics. Concerning maternal reactions to their children's emotions, the results of linear regressions showed that older mothers tend to less comfort children's negative emotions. Moreover, when their children were perceived as more extravert, mothers displayed less comfort reactions to their children's negative emotions. As expected, when mothers had good abilities to express and communicate their emotions and when they perceived their child as less emotionally reactive, they displayed more problem-focused responses (helping to solve the problem that caused the child's distress) to their child's negative emotions. Moreover, when children grow up and when they were perceived as less emotionally reactive, mothers displayed less punitive reactions to their children's negative emotions. Finally, they displayed less discomfort to their children's positive emotions when they had a good knowledge of emotions.

Regarding maternal emotion-related conversations, the higher the mother's level of education, the more they discussed about emotions with their children, and the older they were, the less they discussed.

While, contrary to our expectations, when mothers had good emotional regulation competences, they discussed less about emotions. For paternal model, we observed that both children's and father's characteristics predict their reactions to their children's emotions, particularly for non-supportive reactions. Indeed, for supportive reactions, we obtained a significant model only for encouragement to children's negative emotions: the older they were and the better they expressed and communicated their emotions, the more they encourage their children to express their negative emotions. For non-supportive reactions, we obtained several significant models that are distinct according to specific reactions. Results revealed that fathers displayed more emotional distress when their children grow up. While older fathers tend to less displayed distress to their children's negative emotions and when children were perceived as meticulous, careful and organized. In the same way, punitive responses to children's negative emotions were less used when children were perceived as meticulous, careful and organized. Moreover, we observe that older fathers displayed less minimizing responses to their children's negative emotions, and inversely when they had good emotional regulation competences. Finally, as expected, when fathers had good abilities to express and communicate their emotions and to regulate their emotions, they displayed less discomfort to their children's positive emotions. Concerning paternal emotion-related conversations, results showed that fathers who had a good knowledge of emotions discussed more about emotions with their children.

These findings indicated that parental ERSBs are predicted by both children's and parents' characteristics even if we observed a differential sensitivity between 
mothers and fathers at children's personality. These results are in accordance with previous studies (e.g., [57]) suggesting that parents are not sensitive to the same characteristics of their children. Indeed, mothers seem to be more sensitive to their children's extraversion and emotional stability, while fathers are more sensitive to their children's conscientiousness. Moreover, children's emotional stability and conscientiousness appears to be protective factors for parents' supportive and non-supportive reactions, while a high level of extraversion appears to be a risk factor. Maybe, we can explain these results by literature exploring the links between children's temperament or personality and children's emotion regulation or maladaptive adjustment. Indeed, several aspects of children's temperament or personality have been linked with a high level of emotional regulation, in particular emotional stability. While, the factor of extraversion have been related with a high level of dysregulation. Studies revealed that a high level of negative affectivity [58] or a less level of emotional stability [52] were associated with maladaptive emotion regulation responses or with dysregulation in preschoolers. Moreover, these authors emphasized that children's extraversion is related with emotion regulation abilities, but also with dysregulation. Concerning the potential protective role of the conscientiousness factor, as suggested by Mervielde, De Clercq, De Fruyt and Van Leeuen [59], conscientiousness children have characteristics such as self-control and less behavioural impulsivity and this factor is negatively correlated with externalizing behaviours in childhood. Therefore, we can hypothesised that children high on conscientiousness displayed their negative emotions in more adaptive way than children low on this factor as a result that fathers displayed less distress and punitive responses. Another important result concerns the importance of parents' emotional abilities. Consistently with the meta-emotion philosophy of Gottman et al. [20] [21], we observe that, for both mothers and fathers, good abilities in communication of their own emotions and good knowledge of emotions allowed them to be displayed more supportive ERSBs, such as problem-focused responses or encouragement and conversations about emotions, and less non-supportive ERSBs, such as minimizing responses or discomfort. For parents' emotional regulation competences, we obtained contradictory results. Mothers' emotional regulation competences predict negatively their emotion-related conversations with their children. This result may be explained by the fact that because they have no difficulties to manage their own emotions, mothers are going to be less attentive, by means of emotion-related conversation, to explained causes and consequences of emotions, to ask questions about emotions, etc. Fathers' emotional regulation competences predict positively the use of minimizing responses when their children displayed negative emotions. Maybe, for fathers, minimize their emotions is a efficiency emotional regulation strategy and therefore they react in this way in order to help their children to control their intense negative emotions. On the contrary, their emotion regulation competences help the fathers to feel less in discomfort to their children's positive emotions.

Study 2 adds to a growing literature that emphasized predictive links between 
parents' ERSBs and children's socio-emotional competences but it explores also if children's socio-emotional competences predict these behaviours. Concerning parents' ERSBs that predict children's socio-emotional competences 6 months later, the best predictor corresponds to the children's competences at W1 (for example, children's ToM abilities at W1 explained the majority of variance in children's ToM abilities at W2). However, we obtained several significant models which the addition of parents' ERSBs explained an additional percentage of the variance in children's competences at Wave 2. As in previous researches (e.g., [1] [16] [17]), we obtained distinct results for maternal and paternal models. Mothers' ERSBs predict children's ToM and social adjustment, while fathers' ERSBs predict children's ER. Firstly, results revealed that a high level of maternal emotion-related conversations at W1 predict positively children's ToM at W2 when they have a low level of ToM at W1. On the contrary, these conversations predict negatively children's ToM at W2 when children have a high level of ToM at W1. Secondly, we observe that children were perceived as having better social adjustment at $\mathrm{W} 2$ when mothers displayed non-supportive reactions to their children's positive emotions and when they conversed about emotions at W1. Finally, a high level of paternal emotion-related conversations at W1 predicts positively children's ER at W2 when children have a high level of ER at W1. Regarding children's socio-emotional competences that predict parents' ERSBs 6 months later, as for previous results, the best predictor is parents' ERSBs at W1, but for fathers, we highlighted significant models which the addition of children's socio-emotional competences explained an additional percentage of the variance of parents' ERSBs at W2. Children's ToM and social adjustment at W1 predict negatively paternal supportive reactions to children's positive emotions displayed at W2. Moreover, a high level of children's ER at W1 predicts positively paternal supportive reactions to children's positive emotions at W2 only for fathers who displayed few supportive reactions at W1. In the same way, a high level of children's ER at W1 predicts positively paternal non-supportive reactions to children's negative emotions at W2 only for fathers who displayed few non-supportive reactions at W1.

These results indicated that both mothers and fathers socialize their children's socio-emotional competences, particularly by the way of emotion-related conversations with their children. Indeed, as suggested by previous studies (e.g., [12] [24] [60]), these specific parent-child interactions could support preschoolers' emotional and social development by creating mental representations. These representations allow children to better adjust themselves in emotional or social situations. Our findings are in accordance with these studies by highlighting positive predictive links on one hand, between, maternal-emotion related conversations and children's ToM and social adjustment, and on the other hand, between paternal emotion-related conversations and children's ER. For children's ToM, these conversations are efficiency 6 months later if children's have a low level of ToM abilities. During these interactions, mothers may help their children to understand their mental states and those of others, by explaining 
positive and negative emotions, by asking questions about causes and consequences of emotions, etc. While, contrary to our expectations, maternal emotion-related conversations are going to have a detrimental effect on children's ToM development if their children have a high level of ToM abilities. Because previous researches did not take into account the interaction effects between parents' ERSBS and children's competences, it is difficult to have any explanation, but, maybe, it is due to the children's mental representations. When children have a good system of mental representations about emotions and mental states, emotion-related conversations may confuse the children in their knowledge. Concerning children's social adjustment, as expected, when mothers discuss about emotions with their children at W1, children are perceived as having better social adjustment at W2. For children's ER, our results suggest that children best benefit of their fathers' emotion-related conversations if they have a good level yet in ER. These abilities in emotional regulation allowed the children to be more attentive to their fathers' explanation and discourse about emotions and therefore to improve their ER. Moreover, contrary to previous studies (e.g., [1] [2] [18]) we did not find any positive predictive link between parental supportive reactions and children's socio-emotional competences. On the contrary, we observe that maternal non-supportive reactions to children's positive emotions predict positively their children's social adjustment. These reactions are notably displayed reprimand reactions in social situations, such as express their positive emotions in an intensive way when a baby is sleeping or at a wedding ceremony. Consequently, the use of these reactions may help the children to better understand in which situation they may express their emotions and in what manner. Another important result concerns the effect of children's socio-emotional competences on fathers' ERSBs, while we did not obtained this effect with mothers. Indeed, fathers adapted their behaviours according to their children's competences, by, notably, displayed less supportive reactions when their children have a high level of ToM abilities and social adjustment. These results confirmed the differential sensitivity between mothers and fathers indicated previously: mothers and fathers are not sensitive to the same children's characteristics or competences.

Some limitations or comments need to be considered in these studies. Firstly, it is important to note that, even if we highlighted several significant models, the percentage of variance in score of parents' ERSBs explained by children's and parents' characteristics are very low. Maybe, we can explain these results by the homogeneous nature of our sample. Indeed, our sample was comprised predominantly of Caucasian and had a higher average level of education. Moreover, results of Study 2 could be explained by the fact that children did not performed better in socio-emotional scores after 6 months. Therefore, results need to be interpreted in light of these characteristics and caution applied when generalizing any findings to other populations. Our studies need to be reproduced, for families with a lower level of education or lower socioeconomic status and with an extended time interval or with a third wave 6 months later than W2. Secondly, 
because of the role of language in children's development (e.g., [61]) it would be also interesting to add a measure of children's language ability in order to observe the role of children's level of language in the process of socialization. Finally, it would be interesting that future studies combined the assessment of parents' ERSBs with observation design and self-report measure to reduce the ecological validity bias. Despite these limitations, the results of these studies provide new information about the determinants of parents' ERSBs in preschool period by highlighting those on which we can intervene or not. As already suggested by previous parenting programs [19], it seems important to take into account parents' emotional competences in these program in order to increase their emotional awareness and therefore to improve their ERSBs. Moreover, our results revealed also the importance to include mothers and fathers in parenting program given the distinct role on children's development. Children seem to better benefit of a variety of ERSBs displayed sometimes by fathers and sometimes by mothers. This exposure to diverse behaviours allows the children to construct these mental representations about emotions. Finally, some results confirmed the Parental Socialization of Emotion model of Eisenberg and colleagues [4], but some others results brought a certain nuance by highlighting that according to the situation a non-supportive behaviour could be supportive and inversely.

\section{Acknowledgements}

These studies were conducted with the support of the Chair Baron Frère in Special Education of the Foundation Louvain of the Universite catholique de Louvain.

\section{Conflict of Interest}

There is no conflict of interest in this research.

\section{Ethical Approval}

The ethical committee of the Université catholique de Louvain (Belgium) approves the protocol of these studies. All procedures performed in this study involving human participants were in accordance with the ethical standards of the institutional research committee and with the 1964 Helsinki declaration and its later amendments or comparable ethical standards.

\section{References}

[1] Mazzone, S. and Nader-Grosbois, N. (2016) How Are Parental Reactions to Children's Emotions Related to Their Theory of Mind Abilities? Psychology, 7, 166-179. https://doi.org/10.4236/psych.2016.72019

[2] McElwain, N.L., Halberstadt, A.G. and Volling, B.L. (2007) Mother- and FatherReported Reactions to Children's Negative Emotions: Relations to Young Children's Emotional Understanding and Friendship Quality. Child Development, 78, 14071425. https://doi.org/10.1111/j.1467-8624.2007.01074.x 
[3] Mirabile, S.P., Oertwig, D. and Halberstadt, A.G. (2016) Parent Emotion Socialization and Children's Socioemotional Adjustment: When Is Supportiveness No Longer Supportive? Social Development, n/a.

[4] Eisenberg, N., Cumberland, A. and Spinrad, T.L. (1998) Parental Socialization of Emotion. Psychological Inquiry, 9, 241-273.

https://doi.org/10.1207/s15327965pli0904_1

[5] Belsky, J. (1984) The Determinants of Parenting: A Process Model. Child Development, 55, 83-96. https://doi.org/10.2307/1129836

[6] Prinzie, P., et al. (2004) Parent and Child Personality Characteristics as Predictors of Negative Discipline and Externalizing Problem Behaviour in Children. European Journal of Personality, 18, 73-102. https://doi.org/10.1002/per.501

[7] Fabes, R.A., et al. (2001) Parental Coping with Children's Negative Emotions: Relations with Children's Emotional and Social Responding. Child Development, 72, 907-920. https://doi.org/10.1111/1467-8624.00323

[8] Denham, S.A., Zoller, D. and Couchoud, E.A. (1994) Socialization of Preschoolers' Emotion Understanding. Developmental Psychology, 30, 928-936.

https://doi.org/10.1037/0012-1649.30.6.928

[9] Laible, D. (2011) Does It Matter if Preschool Children and Mothers Discuss Positive vs. Negative Events during Reminiscing? Links with Mother-Reported Attachment, Family Emotional Climate, and Socioemotional Development. Social Development, 20, 394-411. https://doi.org/10.1111/j.1467-9507.2010.00584.x

[10] van der Pol, L.D., et al. (2015) Fathers' and Mothers' Emotion Talk with Their Girls and Boys from Toddlerhood to Preschool Age. Emotion, 15, 854-864.

https://doi.org/10.1037/emo0000085

[11] Jones, S., et al. (2002) Parents' Reactions to Elementary School Children's Negative Emotions: Relations to Social and Emotional Functioning at School. Merrill-Palmer Quarterly, 48, 133-159. https://doi.org/10.1353/mpq.2002.0007

[12] Laible, D. (2004) Mother-Child Discourse in Two Contexts: Links with Child Temperament, Attachment Security, and Socioemotional Competence. Developmental Psychology, 40, 979-992. https://doi.org/10.1037/0012-1649.40.6.979

[13] Hughes, E.K. and Gullone, E. (2010) Parent Emotion Socialisation Practices and Their Associations with Personality and Emotion Regulation. Personality and Individual Differences, 49, 694-699. https://doi.org/10.1016/j.paid.2010.05.042

[14] Wong, M.S., McElwain, N.L. and Halberstadt, A.G. (2009) Parent, Family, and Child Characteristics: Associations with Mother- and Father-Reported Emotion Socialization Practices. Journal of Family Psychology, 23, 452-463. https://doi.org/10.1037/a0015552

[15] Jenkins, J.M., et al. (2003) A Longitudinal Investigation of the Dynamics of Mental State Talk in Families. Child Development, 74, 905-920. https://doi.org/10.1111/1467-8624.00575

[16] LaBounty, J., et al. (2008) Mothers' and Fathers' Use of Internal State Talk with their Young Children. Social Development, 17, 757-775. https://doi.org/10.1111/j.1467-9507.2007.00450.x

[17] Manczak, E.M., et al. (2016) “How Did That Make You Feel?” Influences of Gender and Parental Personality on Family Emotion Talk. Merrill-Palmer Quarterly, 62, 388-414. https://doi.org/10.13110/merrpalmquar1982.62.4.0388

[18] Meyer, S., et al. (2014) Parent Emotion Representations and the Socialization of Emotion Regulation in the Family. International Journal of Behavioral Develop- 
ment, 38, pp. 164-173. https://doi.org/10.1177/0165025413519014

[19] Havighurst, S.S., et al. (2009) Tuning in to Kids: An Emotion-Focused Parenting Program-Initial Findings from a Community Trial. Journal of Community Psychology, 37, 1008-1023. https://doi.org/10.1002/jcop.20345

[20] Gottman, J.M., Katz, L.F. and Hooven, C. (1996) Parental Meta-Emotion Philosophy and the Emotional Life of Families: Theoretical Models and Preliminary Data. Journal of Family Psychology, 10, 243-268. https://doi.org/10.1037/0893-3200.10.3.243

[21] Gottman, J.M., Katz, L.F. and Hooven, C. (1997) Meta-Emotion: How Families Communicate Emotionally. Erlbaum, Mahway.

[22] Shewark, E.A. and Blandon, A.Y. (2015) Mothers' and Fathers' Emotion Socialization and Children's Emotion Regulation: A Within-Family Model. Social Development, 24, 266-284. https://doi.org/10.1111/sode.12095

[23] Ruffman, T., Slade, L. and Crowe, E. (2002) The Relation between Children's and Mothers' Mental State Language and Theory-of-Mind Understanding. Child Development, 73, 734-751. https://doi.org/10.1111/1467-8624.00435

[24] Morelen, D. and Suveg, C. (2012) A Real-Time Analysis of Parent-Child Emotion Discussions: The Interaction Is Reciprocal. Journal of Family Psychology, 26, 998 1003. https://doi.org/10.1037/a0030148

[25] Baker, J.K., Fenning, R.M. and Crnic, K.A. (2011) Emotion Socialization by Mothers and Fathers: Coherence among Behaviors and Associations with Parent Attitudes and Children's Social Competence. Social Development (Oxford, England), 20, 412 430. https://doi.org/10.1111/j.1467-9507.2010.00585.x

[26] Garner, P.W., Dunsmore, J.C. and Southam-Gerrow, M. (2008) Mother-Child Conversations about Emotions: Linkages to Child Aggression and Prosocial Behavior. Social Development, 17, 259-277. https://doi.org/10.1111/j.1467-9507.2007.00424.x

[27] Perry, N.B., et al. (2012) Mothers' Responses to Children's Negative Emotions and Child Emotion Regulation: The Moderating Role of Vagal Suppression. Developmental Psychobiology, 54, 503-513. https://doi.org/10.1002/dev.20608

[28] Warren, H.K. and Stifter, C.A. (2008) Maternal Emotion-Related Socialization and Preschoolers' Developing Emotion Self-Awareness. Social Development, 17, 239-258. https://doi.org/10.1111/j.1467-9507.2007.00423.x

[29] Eisenberg, N., et al. (1999) Parental Reactions to Children's Negative Emotions: Longitudinal Relations to Quality of Children's Social Functioning. Child Development, 70, 513-534. https://doi.org/10.1111/1467-8624.00037

[30] Belsky, J. (1981) Early Human Experience: A Family Perspective. Developmental Psychology, 17, 3-23. https://doi.org/10.1037/0012-1649.17.1.3

[31] De Mol, J. and Buysse, A. (2008) The Phenomenology of Children's Influence on Parents. Journal of Family Therapy, 30, 163-193. https://doi.org/10.1111/j.1467-6427.2008.00424.x

[32] Kuczynski, L. (2003) Beyond Bidirectionality: Bilateral Conceptual Frameworks for Understanding Dynamics in Parent-Child Relations. In: Kuczynski, L., Ed., Handbook of Dynamics in Parent-Child Relations, Thousand Oaks, Sage, 3-24. https://doi.org/10.4135/9781452229645.n1

[33] Parke, R.D., et al. (1994) The Past as Prologue: An Overview of a Century of Developmental Psychology. In: Parke, R.D., et al., Eds., A Century of Developmental Psychology, American Psychological Association, Washington DC. 1-75. 
https://doi.org/10.1037/10155-001

[34] Daffe, V. and Nader-Grosbois, N. (2009) Parental Reactions toward Their Children's Emotions: Combined Version of Two Questionnaires. [Réactions Parentales Face aux Émotions de leur Enfant: Adaptation Intégrée de deux Instruments], In: Nader-Grosbois, N., Ed., Resilience, Regulation and Quality of Life [Résilience, régulation et qualité de vie: Concepts, évaluation et intervention], Presses Universitaires de Louvain, Louvain-la-Neuve, 143-159.

[35] Fabes, R.A., et al. (2002) The Coping with Children's Negative Emotions Scale (CCNES): Psychometric Properties and Relations with Children's Emotional Competence. Marriage \& Family Review, 34, 285-310. https://doi.org/10.1300/J002v34n03_05

[36] Ladouceur, C., Reid, L. and Jacques, A. (2002) Development and Validation of the Questionnaire about Parental Reactions to Positive Emotions Expressed by the Child [Construction et Validation du Questionnaire sur les Réactions Parentales aux Émotions Positives Exprimées par l'enfant]. Canadian Journal of Behavioural Science, 34, 8-18. https://doi.org/10.1037/h0087150

[37] Mazzone, S., et al. (2017) Do Parents Talk about Emotions with Their Children? The Questionnaire of Parent-Child Conversations about Emotions (QPCCE). Psychology, 8, 987-1007. https://doi.org/10.4236/psych.2017.87065

[38] Reicherts, M. (2007) Dimensions of Openness to Emotion (DOE): A Model of Affect Processing, Manual. Department of psychology, University of Fribourg, Fribourg.

[39] Roskam, I., de Maere-Gaudissart, A. and Vandenplas-Holper, C. (2000) The Point of an Instrument to Evaluate Personality in Children Using the Five-Factor Model [Mise au point d'un Instrument d'Evaluation de la Personnalite des Enfants a Partir du Modele a Cinq Facteurs]. Orientation Scolaire et Professionnelle, 29, 661-672.

[40] Engle, J.M. and McElwain, N.L. (2011) Parental Reactions to Toddlers' Negative Emotions and Child Negative Emotionality as Correlates of Problem Behavior at the Age of Three. Social Development, 20, 251-271.

https://doi.org/10.1111/j.1467-9507.2010.00583.x

[41] Nader-Grosbois, N. and Thirion-Marissiaux, A.-F. (2011) Assess the Comprehension of Mental States "Emotions" and "Beliefs" [Evaluer la Compréhension des États Mentaux "Émotions” et “Croyances”]. In: Nader-Grosbois, N., Ed., Theory of Mind: Between Cognition, Emotion and Social Adjusment [La Théorie de P Esprit: Entre Cognition, Émotion et Adaptation Sociale], De Boeck: Bruxelles, 95-125.

[42] Oswald, D. and Ollendick, T. (1989) Role Taking and Social Competence in Autism and Mental Retardation. Journal of Autism and Developmental Disorders, 19, 119127. https://doi.org/10.1007/BF02212723

[43] Flavell, J.H., et al. (1981) Young Children's Knowledge about Visual Perception: Further Evidence for the Level 1-Level 2 Distinction. Developmental Psychology, 17, 99-103. https://doi.org/10.1037/0012-1649.17.1.99

[44] Flavell, J.H. (1986) The Development of Children's Knowledge about the Appearance-Reality Distinction. American Psychologist, 41, 418-425. https://doi.org/10.1037/0003-066X.41.4.418

[45] Perner, J., Leekam, S.R. and Wimmer, H. (1987) Three-Year-Olds' Difficulty with False Belief: The Case for a Conceptual Deficit. British Journal of Developmental Psychology, 5, 125-137. https://doi.org/10.1111/j.2044-835X.1987.tb01048.x

[46] Wimmer, H. and Perner, J. (1983) Beliefs about Beliefs: Representation and Constraining Function of Wrong Beliefs in Young Children's Understanding of Deception. Cognition, 13, 103-128. https://doi.org/10.1016/0010-0277(83)90004-5 
[47] Hutchins, T.L., Prelock, P.A. and Chace, W. (2008) Test-Retest Reliability of a Theory of Mind Task Battery for Children with Autism Spectrum Disorders. Focus on Autism \& Other Developmental Disabilities, 23, 195-206. https://doi.org/10.1177/1088357608322998

[48] Nader-Grosbois, N. and Houssa, M. (2016) Theory of Mind Task Battery: Validation of the French Version [La Batterie de Tâches de Théorie de l'Esprit: Validation de la Version Francophone]. Enfance, 2016, 141-166. https://doi.org/10.4074/S0013754516002019

[49] Hutchins, T.L., Prelock, P.A. and Bonazinga, L. (2012) Psychometric Evaluation of the Theory of Mind Inventory (ToMI): A Study of Typically Developing Children and Children with Autism Spectrum Disorder. Journal of Autism Developmental Disorder, 42, 327-341. https://doi.org/10.1007/s10803-011-1244-7

[50] Houssa, M., Mazzone, S. and Nader-Grosbois, N. (2014) Validation of the French Version of Theory of Mind Inventory (ToMI-vf) [Validation d'une version francophone de l'inventaire de la Théorie de l'Esprit (ToMI-vf]]. Revue Européenne de Psychologie Appliquéel European Review of Applied Psychology, 64, 169-179. https://doi.org/10.1016/j.erap.2014.02.002

[51] Shields, A. and Cicchetti, D. (1997) Emotion Regulation among School-Age Children: The Development and Validation of a New Criterion Q-Sort Scale. Developmental Psychology, 33, 906-916. https://doi.org/10.1037/0012-1649.33.6.906

[52] Nader-Grosbois, N. and Mazzone, S. (2015) Validation of the French Version of Emotion Regulation Checklist (ERC-vf) [Validation de la Version Francophone de l'Emotion Regulation Checklist (ERC-vf)]. Revue Européenne de Psychologie Appliquéel European Review of Applied Psychology, 65, 29-41. https://doi.org/10.1016/j.erap.2014.10.002

[53] Hughes, C., et al. (1997) Social Behaviour in Pervasive Developmental Disorders: Effects of Informant, Group and "Theory-of-Mind". European Child \& Adolescent Psychiatry, 6, 191-198.

[54] Aiken, L.S. and West, S.G. (1991) Multiple Regression: Testing and Interpreting Interactions. Sage Publications, Newbury Park.

[55] Hayes, A.F. (2013) Introduction to Mediation, Moderation, and Conditional Process Analysis: A Regression-Based Approach. The Guilford Press, New York.

[56] Johnson, P.O. and Neyman, J. (1936) Tests of Certain Linear Hypotheses and Their Application to Some Educational Problems. Statistical Research Memoirs, 1, 57-93.

[57] Braungart-Rieker, J., et al. (1998) Infant Affect and Affect Regulation during the Still-Face Paradigm with Mothers and Fathers: The Role of Infant Characteristics and Parental Sensitivity. Developmental Psychology, 34, 1428-1437.

https://doi.org/10.1037/0012-1649.34.6.1428

[58] Santucci, A.K., et al. (2008) Vagal Tone and Temperament as Predictors of Emotion Regulation Strategies in Young Children. Developmental Psychobiology, 50, 205-216. https://doi.org/10.1002/dev.20283

[59] Mervielde, I., et al. (2005) Temperament, Personality, and Developmental Psychopathology as Childhood Antecedents of Personality Disorders. Journal of Personality Disorders, 19, 171-201. https://doi.org/10.1521/pedi.19.2.171.62627

[60] Ontai, L.L. and Thompson, R.A. (2008) Attachment, Parent-Child Discourse and Theory-of-Mind Development. Social Development, 17, 47-60. https://doi.org/10.1111/j.1467-9507.2007.00414.x

[61] Hale, C.M. and Tager-Flusberg, H. (2003) The Influence of Language on Theory of Mind: A Training Study. Developmental Science, 6, 346-359.

https://doi.org/10.1111/1467-7687.00289 